\title{
LA SEMIÓTICA TRIÁDICA DE PEIRCE Y SU APLICACIÓN A LOS GÉNEROS LITERARIOS
}

\author{
Dinda L. Gorlée
}

(Research Center for Language and Semiotic Studies
Indiana University-Bloomington)

CHARLES SANDERS PEIRCE: SU VIDA Y OBRA

El filósofo y matemático Charles S. Peirce (1839-1914), cuyo pensamiento semiótico se discutirá en el presente ensayo, fue hijo de Benjamin Peirce, profesor de matemáticas y astronomía en la Universidad de Harvard, Cambridge (Massachusetts, EE UU), el único matemático estadounidense de su tiempo que gozaba de una reputación internacional. Esto hizo que su hijo Charles creciera y se formara en un ambiente intelectual muy estimulante. Pronto, las inquietudes del joven Charles revelaron un gran talento tanto en matemáticas como en lógica y en ciencias naturales. Más tarde, sus conocimientos enciclopédicos abarcarían la lógica, la filosofía, la química, la astronomía, la biología, así como las ciencias sociales - particularmente sicología y sociología-, entonces en fase embrionaria. Sin ser lingüista, Charles Peirce tenía una gran facilidad para el domino de las lenguas, y en sus escritos discutía frecuente- 
mente temas lingüísticos y relacionados con la lingüística ${ }^{1}$. Por otra parte, no parece que se interesara particularmente por el arte. Aunque el mismo Peirce no desarrollara pensamientos específicos sobre la comunicación artística, el aparato conceptual de su teoría de los signos es perfectamente aplicable al análisis de signos artísticos o estéticos.

En términos generales, Peirce puede caracterizarse como un pensador evolucionista profundamente influido por el darwinismo de su tiempo. Sin embargo, por más que le atrajeran las ideas filosóficas de Darwin acerca de la evolución y el progreso, Peirce nunca llegaba a identificarse con ellas (Pencak, 1991). Para Peirce, la evolución y el progreso no son el producto de un desarrollo continuo que liga, de modo fluido, el pasado con el presente y éste con el futuro -como era predicado por el darwinismo en su variedad más conservadora-Peirce estaba profundamente convencido de que las ideas nuevas sólo pueden ser producto de la ruptura violenta de hábitos previamente desarrollados, que irrumpen en un mundo ordenado a saltos audaces. Sus conjeturas inteligentes son aparentemente caóticas y no se apoyan en nada; sin embargo, ellas solas sientan las bases de todos los descubrimientos científicos, es decir, de todo progreso. Pese a la extraordinaria amplitud de sus conocimientos, Peirce nunca tuvo una carrera universitaria y ni siquiera una posición académica que le hubiera proporcionado el apoyo institucional necesario para que su trabajo tuviera probabilidades de éxito. Durante algunos años impartió cursos de lógica en la Universidad de Harvard y en la Universidad John Hopkins, pero no se le ofreció un puesto fijo e incluso fue despedido. Por este motivo se vio obligado a ganarse la vida trabajando durante casi 30 años en el United States Coast and Geodetic Service. En 1887 cobró una herencia y se retiró a Milford, Pennsylvania. En la relativa soledad de este lugar continuaba escribiendo su obra filosófica.

Para remediar sus estrecheces tuvo que escribir reseñas de libros, particularmente para The Nation, y artículos de diccionario para The Century Dictionary. Se puede quizás decir que en aquel momento Peirce era el mayor filósofo del mundo; pero como vivía y trabajaba en un estado de aislamiento casi total, sin posibilidad de discutir sus ideas con colegas o estudiantes, su obra fue haciéndose más y más especulativa, impenetrable y oscura. Peirce murió a los 74 años, pobre, incomprendido y desconocido.

Si bien las obras publicadas de Peirce consisten hoy en más de 10.000 páginas y varias colecciones de sus escritos han sido publicadas póstumamente, la mayor parte de su obra sigue inédita $\mathrm{y}$, por este motivo, casi desconocida. Los ocho volúmenes de los llamados (mal llamados)

1 El prologuista de Obra lógico-semiótica, el lingüista y sicoanalista canadiense Peraldi, comete un lamentable error al afirmar que «Peirce no era un linguiista, la lengua no le interesaba y no constituye ninguno de sus conceptos» (Peirce 1987:31). 
Collected Papers of Charles Sanders Peirce $(C P)$, que fueron publicados a partir de los años 30, son incapaces de reflejar la extraordinaria profundidad y extensión del pensamiento peirceano. Es una selección limitada, aunque justa y representativa, de textos clave, inéditos hasta esa fecha, organizados según criterios más o menos temáticos. Sin embargo, lo que ofrecen los Collected Papers no es ni más ni menos que una especie de «collage» donde los editores han reunido textos temática y cronológicamente heterogéneos, recortándolos y colocándolos en combinaciones y contextos nuevos. El resultado es, en la terminología de Lévi-Strauss, un trabajo de «bricolage», sin por eso dejar de ser de gran utilidad para todo estudioso serio del pensamiento, tanto semiótico como no-semiótico, de Peirce ${ }^{2}$.

Está en marcha, desde 1982, el ambicioso proyecto de la publicación definitiva de The Writings of Charles S. Peirce; A Chronological Edition $(W)$, donde aparecerá una parte considerable de la obra monumental de Peirce. Hasta la fecha los investigadores han sabido rastrear y reunir más de 90.000 páginas manuscritas inéditas y previamente dispersas - un material que bastaría para llenar unos 65 (!) volúmenes impresos 3 - Por razones prácticas, tal tarea sería quimérica, por lo cual se prevé la edición de unos 30 volúmenes. El volumen 4 (que cubre hasta 1884, cuando Peirce tenía 45 años) apareció en el otoño de 1989. Como no se acelere el ritmo de publicación de los tomos, esto significaría que gran parte de los escritos semióticos más importantes, escritos por Peirce en su período de madurez (a partir de 1902), habrá de permanecer inaccesible para el público hasta bien entrado el siglo XXI. Huelga decir que para los estudios peirceanos, tanto exegéticos como críticos, este retraso sería una verdadera pena.

\section{EL PENSAMIENTO DE PEIRCE}

Tomadas en conjunto, las inquietudes filosóficas de Peirce tenían por objetivo primordial desarrollar el pensamiento de Immanuel Kant (1724-

\footnotetext{
2 Otras importantes colecciones de la obra de Peirce son Semiotic and Significs: The Correspondence between Charles S. Peirce and Victoria Lady Welby, libro editado por Hardwick ( $P W$ en el texto) y The New Elements of Mathematics, a cargo de Eysele ( $N E M$ en el texto). Véanse también las antologías de Buchler (Peirce 1955), Wiener ([1958]1966) (SW en el texto) y, en lengua española, las de Sercovich (Peirce 1986,1987) y Castrillo Criado (Peirce 1988). En la medida de lo posible he consultado y aprovechado, para mi ensayo, las traducciones anteriores de citas de Peirce (y otros autores citados en el presente ensayo); pero aun cuando existía una versión traducida, casi siempre he tenido que modificar el texto para hacer justicia al original. Entre los estudios escritos en lengua española sobre el pensamiento de Peirce hay que mencionar el de Tordera (1978). Véase la bibliografía al final del presente ensayo, donde no figura el desgraciado libro La Semiótica: Guía Alfabética (Barcelona: Anagrama, 1975), especie de versión garabateada, en castellano, del Wörterbuch der Semiotik de Max Bense y Elisabeth Walther.

3 Se espera que con estos datos quede desvirtuada la observación de Sercovich que después de la publicación de los Collected Papers «quedan aún escritos suficientes como para llenar varios volúmenes más» (Peirce 1986:115).
} 
1804), a quien llamó «el Rey del pensamiento moderno» ( $C P: 1.369$, hacia 1885), y quien ejerció una poderosa influencia sobre Peirce, sugiriéndole su teoría filosófica «arquitectónica». El gran tema de la filosofía de Kant fue cómo la síntesis de las apariencias procede según unas leyes necesarias. Para Kant, los juicios sintéticos operan no sólo a base de datos empíricos sino también a base de reglas, que son las que aseguran la objetividad del conocimiento. Peirce escribió a principios de su carrera intelectual:

\begin{abstract}
... Immanuel Kant se preguntó « ¿Cómo son posibles los juicios sintéticos a priori?» Con juicios sintéticos quería decir los que aseveran un hecho positivo y no son una mera ordenación; en breves palabras, juicios tales como los producidos por el razonamiento sintético y los que el razonamiento analítico es incapaz de producir. Con juicios a priori se refería, por ejemplo, a que todos los objetos del mundo externo existen en el espacio, que todo suceso tiene una causa, etc., proposiciones que según él no pueden ser inferidas de la experiencia... Pero antes de hacerse esa pregunta debería haber formulado la siguiente, más general, « ${ }_{i}$ Cómo es que existe la posibilidad de los juicios sintéticos?» ¿Cómo es posible que el hombre observe un hecho y, acto seguido, emita un juicio sobre otro hecho diferente, no implicado en el primero? Tal pensamiento ... carece de ... probabilidad determinada $(C P: 2.690 ; W 3: 303-304,1878)$.
\end{abstract}

La pregunta fundamental que se planteó Peirce fue parafraseada por Savan de la manera siguiente:

\begin{abstract}
¿Cómo se desarrolla la matemática, de tal manera que el matemático pase de principios aceptados a descubrimientos nuevos, sorprendentes? ¿Cómo se desarrolian las ciencias naturales, de tal manera que a partir de observaciones y teorías pasadas, el científico pueda aventurar pronósticos más o menos certeros de sucesos aún no observados? ¿Cómo se desarrolla el pensamiento racional de cualquier tipo que sea -religioso, científico, tecnológico, artístico, filosófico- , incrementando y profundizando su poder sobre la acción, imaginación y vida humanas? (Savan, 1987-1988:1).
\end{abstract}

Tales fueron las preguntas fundamentales que Peirce, lo mismo que otros muchos filósofos antes y después que él, procuró contestar. Peirce trasladó el problema kantiano al proceso de la inferencia sintética y la investigación [inquiry] científica. Él creía que la respuesta se encontraba en la teoría de las «categorías» tal como era desarrollada en su doctrina «semeiótica», la teoría de los signos. Consideraba Peirce que su contribución más notable a la filosofía era precisamente su teoría de las tres categorías universales o modos fundamentales de la realidad.

El 23 de diciembre de 1908, Peirce escribió a su corresponsal inglesa, Victoria Lady Welby ${ }^{4}$, la que fue dama de honor de la Reina Victoria y la primera mujer que se dedicaba a la ciencia semiótica:

4 Desafortunadamente, no he podido averiguar por qué en la literatura peirceana en lengua española, Lady Welby es sistemáticamente llamada Viola en vez de por su legítimo nombre de Victoria. 
... nunca pude estudiar nada - fuera matemáticas, ética, metafísica, gravitación, termodinámica, óptica, química, anatomía comparada, astronomía, sicología, fonética, economía, historia de la ciencia, juegos de naipes, hombres y mujeres, vino, metrología一, salvo como un estudio de semiótica.(PW:85-86)

Quizás hubiera escrito estas palabras en son de medio burla; pero tienen un fondo de verdad. Las publicaciones más tempranas de Peirce, que se remontan a 1867-1868, ya proponen una teoría semiótica extensa y general; y gran parte de lo que más tarde escribió sobre la teoría de los signos es un desarrollo - radical, innovador, al igual que el espíritu de toda la doctrina peirceana - de su semiótica anticipada. La base de su semiótica la constituyen las categorías universales, "primeridad», «segundidad» $\mathrm{y}$ «terceridad», correspondientes aproximadamente a los modos de ser - posibilidad, hecho actual y ley $(C P: 1.23,1903)$ - Esta teoría, que más tarde llamaba «fenomenología» o «faneroscopía», está fundada en los estudios que Peirce hizo de Kant y de la lógica. Peirce argumentó convincentemente que todo pensamiento consiste en signos. Pero mientras al principio consideró la lógica como una rama de la semiótica, más tarde llegó a ensanchar su concepto de la lógica y a identificarla con la semiótica. Antes de dar una exposición de su pensamiento semiótico, esbozaré primero su temprana teoría de las categorías, subyacente a su lógica (y por lo tanto a su semiótica).

\section{LAS CATEGORÍAS}

En fecha temprana 5 , Peirce identificó el pensamiento y el razonamiento con las tres maneras de experimentar el mundo y la realidad, es decir con los signos. Las categorías — primeridad, segundidad, terceridadconstituyen la clave, base y núcleo de la obra y el pensamiento de Peirce, y serán, por lo tanto, enfocadas aquí desde los diversos puntos de vista que requiere la discusión de los diferentes aspectos de la obra peirceana. Me permito repetir a continuación el texto - algo retocado- de unos párrafos que escribí hace algunos años a propósito de la primeridad, segundidad y terceridad:

De las tres maneras de percibir hechos, la primeridad es quizás la más difícil de entender, a pesar de representar lo que Peirce llama la «pristina simplicidad» (CP:8.329). La primeridad significa las ideas de sentimiento espontáneo, no anali-

5 Véase su «Sobre una nueva lista de categorías» [On a new list of categories] ( $C P: 1.545$ $1.549 ; W 2: 49,1867)$. 
zado, instantáneo e inmediato; es como es, de manera directa, sin preocuparse por continuidad ni lógica ni depender, para su comprensión, de nada que no sea de lo que presenta ella misma. Por ejemplo, se experimenta la primeridad al sentir un dolor agudo, un choque eléctrico, el estremecimiento de un placer físico, la sensación total de lo rojo o de lo negro, el sonido estridente del silbido de un tren, un olor penetrante ${ }^{6} 0$ cualquier otra impresión fuerte y llamativa que se impone a la mente, forzándola a reconcentrarse en el fenómeno --pero reconcentrarse instintivamente, sin reflexionar. El mismo Peirce incluía también en su enumeración de Primeros a «la cualidad de la emoción de quien contempla una hermosa demostración matemática, la cualidad del enamoramiento» $(C P: 1.304)$. En síntesis, la primeridad es la idea del momento presente y atemporal, y es experimentada como «pura emoción del tout ensemble» $(C P: 1.311)$. Un Primero no se puede "pensar», pues entonces perdería irremediablemente su carácter de Primero. (Gorlée 1987:46).

Mientras la primeridad significa unidad indivisible, la segundidad implica la idea dinámica de alteridad, de conciencia bi-polar, la experiencia de acción-estímulo y reacción, de causa y efecto, de cambio y resistencia al cambio. La doble idea de pegar y ser pegado encarna perfectamente la segundidad, pues encierra los elementos de comparación, contraste, interacción y lucha. Un primero es inaprensible, "sólo algo que pudiera realizarse», una potencialidad o posibilidad; en cambio, un segundo es un hecho concreto, «un suceso... algo que ocurre realmente» ( $C P: 7.538)$. En palabras de Peirce, «lo real es lo que exige insistentemente que se lo reconozca como algo distinto de una creación de la fantasías ( $C P: 1.325)$. Por este motivo, hacemos frente a la realidad, valiéndonos de la segundidad, y en este proceso hacemos experiencia de la vida. Todo conocimiento del mundo de los hechos y de los aspectos más bien prácticos de la vida humana - como son abrir una puerta, hacer una llamada telefónica y lanzar un balón-implica forzosamente segundos. La segundidad entra en juego cada vez que hacemos un esfuerzo, tomamos una decisión, descubrimos algo, nos orientamos en el espacio o en el tiempo, o cuando algo nos coge de sorpresa ( $C P: 5.52-5.58)$. La segundidad difiere de la primeridad en que ocurre aquí y ahora, pero al mismo tiempo está basada en lo que se ha aprendido a través de experiencias pasadas. Peirce decía que «podemos decir que la mayor parte de lo que se hace en la realidad consiste en segundos - 0 mejor dicho, la segundidad es el carácter predominante de lo que ha sido hecho" (CP:1.343) (Gorlée 1987:46).

Más allá de la vaguedad y generalidad inherentes en la primeridad, «una mera idea sin realizar», y la forma concreta e individualizada de la segundidad, «los casos a los que es aplicada [la primeridad]" ( $C P: 1.342)$, la terceridad viene a representar la ley general que rige el sentimiento (primeridad) y la acción (segundidad), otorgándoles continuidad. Como esta ley general establece explicaciones racionales, toda actividad intelectual es un Tercero. El pensamiento lógico, la terceridad, crea orden y regularidad a partir de caos y azar. «El hilo de la vida es un tercero» $(C P: 1.377)$, pues la terceridad inherente le presta una continuidad que nos permite efectuar una predicción y adoptar la actitud conveniente con respecto a hechos futuros.

Según Peirce, se trata de una clase de conciencia que no puede ser inmediata, porque abarca un cierto tiempo, no sólo porque continúa a través de cada instante de ese tiempo, sino porque no puede ser contraída en un único instante. Difiere de la conciencia inmediata del mismo modo que una melodía difiere de una nota prolongada. Tampoco puede la conciencia de los dos aspectos de un instante, de un suceso súbito, en su realidad individual, abarcar la conciencia de un proceso. Ésta es la conciencia que liga nuestra vida. Es la conciencia de la síntesis (CP:1.381).

6 Estos ejemplos están tomados de Peirce. 
Todos los sentimientos «elevados» y emociones «hondas», como son el amor, la esperanza y la devoción religiosa, y que son comúnmente considerados sofisticados y, por eso, exclusivos para la especie humana, son terceros. Lo mismo reza, $a$ priori, para la cognición, la inteligencia y el desarrollo mental. (Gorlée 1987:47).

Peirce enseñaba que si bien nuestro conocimiento cognitivo no se limita a los signos y tenemos conocimiento de objetos no significados, sin embargo todo conocimiento es necesariamente en signos. Pensamos en signos. «No tenemos ninguna facultad de pensar sin signos», ya observó el joven Peirce al respecto $(C P: 5.265 ; W 2: 213,1868)$; y «la vida no es sino una secuencia de inferencias, una serie de pensamientos» (CP:7.583; $W 1: 494,1868)$. Los pensamientos-signos reflejan los diferentes modos en que hacemos significar los fenómenos de la realidad. Según esto, los tres argumentos - llamados «abducción», «inducción», «deducción»- son terceros complejos, signos triádicos que, a su vez, implican y están compuestos de segundos y primeros.

\section{RAZONAMIENTO Y LÓGICA}

La investigación [«inquiry»] científica está siempre inspirada por el afán de saber, la curiosidad intelectual. Aguijoneado algún observador por la apariencia sorprendente, problemática o misteriosa de algún fenómeno, suceso u objeto «cuya extrañeza le impresiona» (MS 634:5, 1909), se siente estimulado a investigarlo. A fin de conocer, explicar e interpretar tal fenómeno, suceso u objeto, y de formar una predicción con respecto a su naturaleza o conducta en el futuro, lo estudia minuciosamente. A continuación, el investigador se pone a hacer las reflexiones propias del caso, tomando como punto de partida los datos obtenidos en su observación. La investigación y su(s) conclusión(es) tendrán más validez científica si el ejercicio mental es sistematizado de suerte que el riesgo de subjetividad quede minimizado a la objetividad maximizada.

Para realizar tal propósito final - la objetividad - los datos obtenidos en la percepción sensorial y mental del fenómeno - su observaciónson filtrados y mediatizados por algún tipo de razonamiento inferencial, que consiste en un procedimiento triple cuyas conclusiones, según Peirce, han de considerarse como verdaderas, por lo menos a largo plazo.

Tradicionalmente, el razonamiento válido podía ser o deductivo o inductivo. Peirce revolucionó esta dicotomía al añadirle un tercer tipo de argumento y así redefinir la dicotomía como una tricotomía. La nueva clasificación era, en palabras del propio Peirce, nada menos que «la cla- 
ve de la lógica» (NEM4:22, 1904). La clasificación peirceana distingue entre razonamiento explicativo (o razonamiento analítico) por un lado y razonamiento ampliativo (o razonamiento sintético) por otro -éste otra vez subdividido en dos-.

El razonamiento explicativo o analítico corresponde a lo que habitualmente se llama razonamiento deductivo. En él, los hechos afirmados en las premisas son sencillamente sustituidos por lo que está implícito en ellas. Como inferencia que es desde el todo hacia las partes, no se apoya en lo desconocido ni lo parcialmente (des)conocido. Esto hace que la deducción sea la única forma de razonamiento necesario. Por otra parte, el razonamiento ampliativo o sintético no lleva a conclusiones necesarias, sino a conclusiones probables, verosímiles o sólo plausibles. El razonamiento ampliativo fue subdividido por Peirce (en 1866) en dos tipos: inducción - el tipo tradicional de razonamiento probable - y abducción - también llamada hipótesis o retroducción por su «inventor», Peirce. Tanto inducción como abducción son formas inferenciales desde las partes hacia el todo; por consiguiente, las dos están lejos de alcanzar certeza o producir verdad. «La deducción prueba que algo tiene que ser» y «La inducción indica que algo realmente es operativo»; en cambio, «La abducción sólo propone que algo puede sen» (CP:5.171, 1903).

Fuera de las diferencias mencionadas arriba, los tres tipos de argumento lógico coinciden en que implican la formación y el uso de hipótesis. No hay investigación, sea científica o práctica, que no use el razonamiento instintivo en el que se basa la abducción: todo investigador tiene que formular y adoptar ciertas hipótesis para fundamentar su argumentación. Citando el famoso ejemplo peirceano del saco de judías, la abducción se define como sigue:

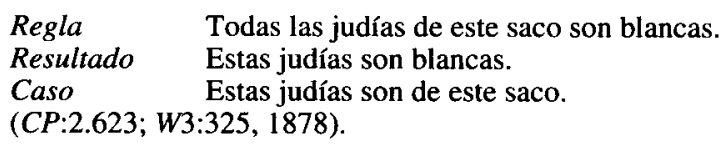

Entre los tres argumentos, la abducción es la única que «abre nuevos horizontes» (NEM3:206, 1911) y da comienzo a nuevas ideas en la investigación científica $(C P: 6.531,1901 ; C P: 7.220,1901)$. Por más débil que sea la seguridad absoluta de que la abducción produzca conclusiones verdaderas - comparado con la fuerza probatoria de sus contrapartidas inductivas y deductivas-, es sin embargo en la abducción donde reside la fuerza creativa de cualquier argumentación, la que inspira originalidad en lo que, sin ella, sería un procedimiento «razonable» $(C P: 5.174,1903)$ pero un procedimiento racionalista $\mathrm{y}$, por eso, carente de vitalidad, muerto. 
En su embrionario «Espécimen de un diccionario de los términos de la lógica y ciencias afines: $\mathrm{De} A$ a $\mathrm{ABS} »[\ll$ Specimen of a dictionary of the terms of logic and allied sciences: A to ABS»] (W2:108, 1867), Peirce inventó e introdujo el término técnico de «abducción» como complemento $y$, en cierto sentido, como fundamento de la pareja tradicional formada por deducción e inducción. Así Peirce bautizó una modalidad de pensar «lógicamente» que, a pesar de su carácter provisional, resulta muchas veces más plausible de lo que su denominación anterior, hipótesis, parecía indicar. En efecto, la abducción tal como la caracterizó Peirce, desborda con creces los límites de las meras conjeturas e incluso es la responsable del desarrollo intelectual y del progreso científico. Desprovisto de las ideas generadas abductivamente por una mente educada, guiada por, en palabras de Peirce, «il lume naturale, el que alumbraba los pasos de Galileo» $(C P: 1.630,1898)$, el sistema de la lógica carecería de toda inventiva e iniciativa. Sin heurística abductiva, pecaría, además, de autosuficiente y se convertiría en mecanismo puramente automático; le faltaría inspiración para descubrir algo nuevo. La abducción corresponde, en el paradigma triádico de Peirce, a la primeridad, la primera de sus categorías universales. El típico signo de primeridad es el «icono», que representa su objeto gracias a su similitud o analogía con él; comparte con su objeto una o más cualidades. La abducción es argumento icónico, pues la conclusión de un silogismo abductivo - es decir, la explicación provisional del fenómeno problemático- está prefigurada icónicamente en las premisas. La primera premisa describe la cualidad de las judías de este saco $(C P: 2.96,1902)$, estableciendo el criterio de comparación que se repite en la conclusión o interpretante. La cualidad icónica es, en el ejemplo del saco de judías, la blancura.

Tras la abducción, a la cual Peirce calificó de «ancla de la esperanza de la ciencia» (MS691:118, 1901), examinemos ahora cómo funciona el segundo tipo de argumento lógico, la inducción:

\footnotetext{
Caso Estas judías son de este saco.

Resultado Estas judías son blancas.

Regla Todas las judías de este saco son blancas.

(CP:2.623, W3:325, 1878).
}

Peirce entendió por silogismo inductivo «un método de investigación experimental» $(C P: 5.168,1903)$. Esto presupone que «lo que es verdad en el caso de un número de pruebas hechas al azar es también verdad para toda la colección de la cual las pruebas están tomadas», y por este motivo «podría llamarse argumento estadístico» (CP:5.275; W2:217, 1868). Como la parte indica directamente el todo (ya que comparten una misma cualidad), la primera premisa de la inferencia inductiva constituye un 
«índice» de la conclusión. En la semiótica de Peirce, el índice es un signo de segundidad, que se encuentra en una relación de contigüidad o proximidad directa con su objeto. Señala fuera de sí mismo, hacia su objeto. De esta manera, la presencia de humo significa fuego - un fuego invisible o ausente, tal vez, pero que constituye el complemento natural del humo, y es una consecuencia directa de él. Para describir el índice, Peirce utilizó la imagen del «fragmento arrancado del objeto, siendo ambos en su existencia un todo o parte de ese todo" $(C P: 2.230,1910)$. Por esta razón, la inducción es argumento indicativo, indicial: pues establece entre premisa y conclusión una relación de causa y consecuencia tan clara y directa que apenas requiere, para su interpretante, a un intérprete pensante, inteligente.

Sin embargo, la inducción no proporciona seguridad absoluta, pues el investigador ha de basarse en una hipótesis (débil o fuerte, pero una hipótesis) para formular su conclusión, que tiene carácter predictivo porque juzga lo desconocido por lo conocido. La inducción es una generalización justa o injusta, que se permite extrapolar conocimiento nuevo a partir de hechos observados y reales.

Tal procedimiento es perfectamente aceptable, mientras se tiene en cuenta que los hechos afirmados en las premisas pueden ser incompletos o incluso falsos, lo cual desvirtuaría todo el argumento. Pero esto no impide que «el razonamiento proceda como si todos los objetos que posean ciertos caracteres fueran conocidos» $(C P: 5.272 ; W 2: 216,1868)$.

Este optimismo por parte del investigador está también dramatizado en la llamada «máxima pragmática» [«pragmatic maxim»] que formuló Peirce en su famoso ensayo, de 1878, titulado «Cómo clarificar nuestras ideas» [«How to make our ideas clear»], que junto con la teoría de las tres categorías universales constituye la base de la carpintería de todo el edificio lógico-semiótico de Peirce. ${ }^{7}$ De acuerdo con este principio fundamental del pragmatismo, Peirce estaba convencido de que «cualquier investigación, si es llevada hasta el final, tiene el poder vital de la autocorrección y del crecimiento» $(C P: 5.582,1898)$. Según Peirce, la inducción conducirá al investigador honesto y serio a medio camino entre la duda, la interrogación inicial y la meta final, la certeza de la verdad. En esta trayectoria, la inducción constituye la etapa intermedia, en la que «sólo sabemos que, en aceptando las conclusiones inductivas, nuestros errores se contrapesarán, a largo plazo» $(C P: 5.350,1868)$. Véase la siguiente definición:

Llamo inducción a la operación que consiste en experimentar una hipótesis; si es válida, las observaciones hechas en ciertas circunstancias deberán dar ciertos re-

7 La máxima pragmática de Peirce será citada y discutida más adelante en este artículo. 
sultados; y tras cumplir aquellas circunstancias y observar los resultados, si son favorables, dar una cierta confianza a la hipótesis. (CP:6.526, hacia 1901).

La inducción tal como la definió Peirce en este período crucial de su pensamiento, produce una «verdad práctica» (CP:6.527, hacia 1901), «proporcionándonos una seguridad razonable de ampliar nuestro conocimiento positivo» $(C P: 2.96,1902)$. La conclusión de una inducción, sin embargo, siempre «queda sujeta a una probable modificación para adecuarse a futuros experimentos» $(C P: 2.96,1902)$.

Una típica inferencia deductiva sería la siguiente:

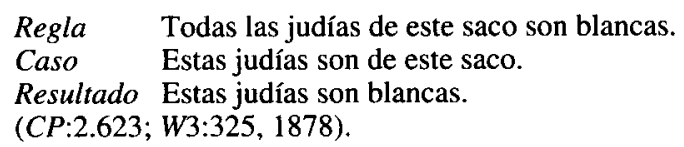

Mientras, en la inducción, «generalizamos desde un número de casos en los que se representan hechos verdaderos, e inferimos que los mismos hechos son verdaderos en la totalidad de casos de esta clase» ( $C P: 2.624$, 1878), en la deducción - argumento del que el razonamiento matemático es el ejemplo modelo- «se aplican reglas generales a casos particulares» (CP:6.620, 1878). Aquí, la inferencia de una conclusión a partir de las premisas es una operación puramente metódica, casi mecánica $(C P: 5.579,1898)$, pues la premisa de un silogismo deductivo proporciona la regla general, o verdad, que incluye la conclusión, referida ésta a un caso particular. Siendo la premisa, con respecto a la conclusión, un signo de terceridad, la deducción puede caracterizarse como argumento simbólico —en el sentido específico del concepto de «símbolo» en la doctrina peirceana.

Para Peirce, un signo es simbólico cuando su relación con el objeto está abstraída de la realidad y no es natural. Por consiguiente el símbolo sólo puede significar si es interpretado de acuerdo con una regla convencional y arbitraria. Entre productor e intérprete del signo simbólico debe haber, pues, concordancia de opiniones al respecto; si no, no hay comunicación posible. El hecho de que, en ciertas circunstancias, una paloma pueda significar paz ( $y$, otro ejemplo, una bandera, la patria), presupone conocimientos comunes, culturalmente determinados. Por consiguiente, el símbolo sólo puede funcionar si los miembros de la comunidad cultural han aprendido a usarlo como tal. Esto hace también que los símbolos, a diferencia de los signos «naturales», signifiquen la pertenencia (o no pertenencia) a un determinado grupo social. Sirva de ejemplo típico la lengua. Los signos lingüísticos, tanto escritos como hablados, son en pri- 
mer lugar signos simbólicos, arbitrarios, adoptados por convenio social; sólo tienen significado para el lector, oyente, etc. que domine el complejo sistema de reglas que rige una lengua particular.

La deducción es «el único tipo de argumento compulsivo» $(C P: 2.96$, 1902); en vivo contraste con la abducción y la inducción, la deducción casi «puede ser practicada por una máquina» $(C P: 5.579,1898)$. Esto implicaría que, según Peirce,

Teóricamente,..., no existe la posibilidad del error en el razonamiento necesario... En la práctica, y de hecho, las matemáticas no están exentas de aquella propensión al error que afecta todo quehacer humano. Estrictamente hablando, no es seguro que dos por dos sea cuatro (CP:5.577, 1898).

Esto quiere decir que ni siquiera la inferencia deductiva proporciona siempre la verdad absoluta. Su validez «depende incondicionalmente de la relación entre el hecho inferido y los hechos afirmados en las premisas» $(C P: 5.270 ; W 2: 215,1868)$, de suerte que, a partir de premisas verdaderas, la deducción debe producir necesariamente conclusiones verdaderas ( $C P: 5.271 ; W 2: 215,1868)$. Pero hay que añadir aquí que la deducción misma no se dedica a examinar la validez de las hipótesis afirmadas en sus propias premisas; se supone sencillamente que son correctas pues «representan la totalidad de nuestro conocimiento del caso» (CP:5.271; $W 2: 216,1868$ ). Al excluirse la posibilidad de evaluar críticamente las premisas, no es posible introducir nuevas ideas, ni rechazar una hipótesis una vez que ha sido admitida. Esto señala claramente los límites y las virtudes del pensamiento deductivo: explicativo por excelencia, es incapaz, de por sí, de ampliar nuestro conocimiento.

Basten por el momento estas observaciones sobre la tricotomía peirceana de los argumentos. Evidentemente, el objetivo de cualquier tipo de razonamiento será sencillamente el de «averiguar, a partir del estudio de lo conocido, otra cosa aún desconocida» $(C P: 5.3 ; W 3: 244,1877)$. Es éste el proceso denominado por Peirce «la fijación de la creencia» [ «The fixation of belief»] (CP:5.358-5.387; W3:242-257, 1877), proceso que va desde la duda hasta la creencia y desde lo individual hasta lo colectivo, con el objeto de llegar a un acuerdo de las opiniones. Tal proceso corresponde también a la «búsqueda cognitiva» de la verdad, de Ransdell, el gran crítico de Peirce; y Ransdell describe esta «búsqueda cognitiva» también con otro término, una metáfora con sabor antropológico, a saber una 
metáfora. Los humanos éramos cazadores antes de ser guerreros o incluso cultivadores: siempre estaremos a la caza de algo. La objetividad toma la forma de una caza colectiva de la verdad, y me parece que esto es exactamente lo que debería significar la palabra científico. (Ransdell 1986a:238).

En efecto, en el pensamiento maduro de Peirce - los últimos 15 a 20 años de su vida - los grados de verdad que pueden ser vehiculados por los diferentes tipos de argumento, ocupan un puesto central. En este empeño, la idea absoluta de la verdad objetiva, tal como es generada por el razonamiento necesario, es abandonada y sustituida por los varios matices de «probabilidades subjetivas, o verosimilitudes, que tan sólo expresan la conformidad de una nueva sugerencia a nuestras disposiciones» (CP:2.777, 1901).

\section{EL PRAGMATICISMO DE PEIRCE}

En 1878, Peirce formuló la «máxima pragmática» [«pragmatic maxim»] que, en su versión más conocida, reza como sigue:

Considérese qué efectos, que pudieran tener concebiblemente repercusiones prácticas, concebimos que tiene el objeto de nuestra concepción. Entonces, nuestra concepción de esos efectos es la totalidad de nuestra concepción del objeto. (CP:5.402; W3:266, 1878; cf. versiones posteriores: $C P: 5.9,1902 ; C P: 5.412$, 1905; MS318:256-257, 1907).

Decía Peirce que el pensamiento tiene por objetivo «dilucidar el sentido de las palabras concretas y conceptos abstractos» (CP:5.464, 1907); el significado establecido es su contenido intelectual general. Efectivamente, la máxima pragmática constituye un elemento básico de la teoría general del significado. El pensamiento es para él una acción mental que elimina la duda, estableciendo una creencia que lleva a un hábito o norma de pensar. Para Peirce, establecer el significado es un proceso progresivo, en el que los conceptos producen tres efectos lógicos. Es decir, son interpretados en tres fases sucesivas en las que son «clasificados» hasta alcanzar la verdad objetiva.

Durante los 25 años que siguieron a la formulación de su máxima pragmática, Peirce no se ocupó mucho del pragmatismo, sino que se dedicó principalmente al estudio de las categorías, la clasificación de las ciencias y la teoría general de los signos. Sin embargo, el ideario y el 
aparato conceptual que desarrolló en este largo «intervalo», fueron plenamente integrados en la versión peirceana del pragmatismo - al cual rebautizó con el nombre de «pragmaticismo» para distinguirlo del pragmatismo más general de su amigo y colega de toda la vida, el filósofo William James.

En 1905, Peirce describió el pragmaticismo como «un método de determinar el significado de cualquier concepto, doctrina, afirmación, palabra u otro signo» $(C P: 5.6,1905)$; y dos años más tarde escribió:

A mi modo de ver el pragmatismo es un método de determinar los sentidos no de todas las ideas sino sólo de lo que yo llamo «conceptos intelectuales», es decir de aquellos conceptos sobre cuya estructura reposan argumentos relacionados con el hecho objetivo (MS318:134, 1907).

Así, a partir de la serie de conferencias que impartió en la Universidad de Harvard en 1903, Peirce asociaba el pragmaticismo con la terceridad, la categoría de los símbolos. El pragmaticismo peirceano explica y se ocupa del significado de los «conceptos intelectuales», mencionados arriba, que una mente va produciendo; un significado que es constituido por una serie infinita de «interpretantes», es decir signos que interpretan signos anteriores. Peirce nunca dejará de ser un típico hombre de laboratorio; su «procedimiento científico» ya no está guiado por creencias personales y prácticas — como fue el caso en el pensamiento temprano de Peirce- sino por creencias teóricas y científicas, es decir, por juicios verificables experimentalmente, que son a su vez el resultado de una hipótesis abductiva. En la doctrina pragmática peirceana, el razonamiento lógico, para ser válido, ha de ser acción sígnica (auto)controlada; en otras palabras, es diseñada como «semiosis», el proceso cognitivo que nos permite acercarnos cada vez más a lo que constituye el propósito final de todo pensamiento racional. Según esto, pensar es interpretar semiósicamente en la medida en que consiste en acción consciente, orientada hacia el futuro y cuya naturaleza evolutiva hace que en algún momento hipotético del futuro pensamiento llegue a unificarse, a habitualizarse; y según la doctrina peirceana, esta progresiva «fijación de la creencia» y «clarificación de conceptos» dará como resultado final el llamado «summum bonum» 8 .

En 1905, Peirce reformuló la máxima pragmática en términos más semióticos, así:

8 Para una discusión detallada del pragmatismo de Peirce, véase Fitzgerald 1966:91ss. y Kent 1987:192ss. 
La totalidad del significado intelectual de un símbolo consiste en el total de todos los modos generales de conducta que, condicionales a todas las diferentes circunstancias y deseos posibles, resultarían en la aceptación del símbolo ( $C P: 5.438$, 1905).

En su época madura Peirce casó, por decirlo así, las tres categorías - y por ende su lógica más temprana, de los tres argumentos- con su pragmaticismo. En su nueva formulación, el pragmaticismo tendría particular importancia para su semiótica; pues partiendo de un universo «blando», hecho de pura irregularidad y azar, el hombre pragmático se embarca en un proceso en el que el universo se va poco a poco «fortaleciendo». Tal génesis evolutiva no es sino el camino de la ciencia, que, para Peirce, requiere continua experimentación para autocontrolarse y autocorregirse. La ciencia nunca puede ser doctrinal y estática sino que posee carácter dinámico y experimental.

Aunque Peirce afirmara que el pragmaticista se dedica a la «lógica racional experimental» $(C P: 5.430,1905)$, esta afirmación no implicaba para él que los hábitos y la generalidad fuesen producto exclusivo de alguna actividad humana. El antropomorfismo es sin duda rasgo característico de muchos fenómenos, pero es perfectamente posible analizar mecanismos autocontroladores naturales pero no humanos. Para Peirce, el proceso cognitivo humano puede «naturalizarse» y aplicarse a fenómenos naturales. Durante medio siglo, la trayectoria intelectual de Peirce como pensador evolucionista iba precisamente dirigida a demostrar que el pensamiento, espíritu o «mente» [«mind»], no se opone a la naturale$\mathrm{za}$, o «materia» [«matter»], sino que existe entre ambos una relación de continuidad. Esto quiere decir que la actividad cognitiva y todos los fenómenos naturales son isomorfos, y que la interacción experimental entre los humanos y la naturaleza no emana exclusivamente del punto de vista de un yo subjetivo, sino que toda acción humana se sitúa dentro de la procesualidad «arquitectónica» de la semiosis. Así, empieza como una hipótesis que, a fuerza de experimentación, queda progresivamente «clarificada», haciéndose cada vez más «fuerte». Tal procedimiento jerárquico tiene un origen abductivo que, confirmado inductivamente, resulta en una forma deductiva - el summun bonum, la verdad tal como es.

La procesualidad trifásica es, según el paradigma peirceano, universal y puede aplicarse a todos los procesos lógicos (es decir, para Peirce, todos los procesos semióticos). Esto puede ilustrarse aquí con algunos ejemplos tomados de diferentes campos de investigación científica, donde se dramatiza, de diferente modo, la tricotomía peirceana, así:

Lógica Hipótesis, Inducción, Deducción (CP:1.354, 1890-1891; CP:1.369, hacia 1885); Nombres (Términos), Proposiciones, Inferencias $(C P: 1.369$, hacia $1885 ; C P: 1.354,1890-1891) ; C P: 1.369-1.372$, ha- 


\begin{abstract}
Metafísica Yo, Ello, Tú (CP:1.551, 1867); Espíritu, Materia, Evolución ( $C P: 6.32,1891)$; Origen, Fin, Mediación (Medio. Enlace) $(C P: 6.32$, 1891); Pluralismo, Dualismo, Monismo (CP:6.32, 1891); Mente, Materia, Dios (W1:83, 1861).

Física Indeterminación, Hecceidad, Proceso (CP:1.405, 1890-1891); Azar, Ley, Hábito (CP:1.409, 1890-1891; CP:6.32, 1891); Posición, Velocidad, Aceleración ( $C P: 1.337$, hacia $1875 ; C P: 1.359,1890-$ 1891); Inercia, Fuerza, Causalidad ( $C P: 1.66-1.69,1903)$.

Biología Sensibilidad, Movimiento, Crecimiento (CP:1.393, 1890-1891); Variación arbitraria, Herencia, Selección (Fijación) (CP:1.398, 1890-1891); $C P: 6.32,1891$ ); Instinto, Experiencia, Hábito $(C P: 8.374,1908)$.

Fisiología Excitación celular, Transferencia de la Excitación, Excitación Habitual (CP:1.393, 1890-1891); Irritación, Reflejo, Repetición (CP:5.373, 1877; $C P: 3.156-3.157,1880)$.

Psicología Sentimiento, Voluntad, Conocimiento (CP:1.375, 1890-1891); $C P: 1.382,1890-1891)$; Sentimiento, Reacción, Concepto General (CP:6.32, 1891); Sentimiento, Acción (Resistencia), Aprendizaje (CP:1.377, 1890-1891); Instinto, Deseo, Propósito (CP:7.369, 1902)9
\end{abstract}

\title{
SIGNO
}

Para definir y describir el concepto peirceano del signo, es necesario contestar a dos preguntas: (1) ¿Qué tipo de «cosas» pueden ser signos? y (2) ¿Cuáles son las características de un signo?

En respuesta a la primera pregunta, Peirce explicó que él incluía

...en el término de «signo» a cualquier imagen, diagrama, grito espontáneo, señal con el dedo índice, guiño, nudo en el pañuelo, recuerdo, sueño, fantasía, concepto, indicio, seña, síntoma, letra, numeral, palabra, frase, capítulo, libro, biblioteca. $(M S 74: 3$, s.a.)

\section{y en otro escrito insistió en que}

9 Para esta sección me he inspirado en el texto de Esposito (1980:174-175). La mayoría de las tríadas mencionadas están tomadas del ensayo «A guess at the riddle» (1890-1891) u otros escritos de fin de siglo, antes de que la teoría de la relatividad y la teoría cuántica revolucionaran las ciencias. La mayoría de las tricotomías están explícitamente mencionadas por Peirce; algunas son extrapolaciones del texto peirceano. 
Los signos en general [forman] una clase que incluye imágenes, síntomas, palabras, frases, libros, bibliotecas, señales, ordenes y mandatos, microscopios, apoderados legales, conciertos musicales y sus interpretaciones,... (MS634:18-19, 1909)

Para Peirce no había ninguna duda de que cualquier objeto, fenómeno o suceso «conocible» $(C P: 8.177$, s.a. $)$ - es decir, perceptible o imaginable- puede ser un signo. Así, pueden ser signos tanto cualidades (signos de primeridad), cosas que existen u ocurren realmente (signos de segundidad), como pensamientos, leyes y hábitos (signos de terceridad). Sin embargo, un signo no ha de considerarse como una especie de cosa: el mundo no puede dividirse en dos tipos de cosas por separado - los signos y los no-signos-, cada cual con sus subdivisiones excluyéndose mutuamente. No hay nada que no pueda ser un signo. Desde una perspectiva realmente amplia se podría decir que todo es un signo: «todo este Universo está bañado de signos e incluso está compuesto única y exclusivamente de signos», decía Peirce (CP:5.448, nota 1, 1905). Toda cognición humana -incluyendo la percepción sensorial, sentimientos y emociones, así como el razonamiento inferencial- implica signos. Pero el signo no existe si no actúa como tal: es decir, si no entra en una relación con su «objeto», es interpretado y produce un nuevo signo, su «interpretante». Este proceso de representación e interpretación se llama acción sígnica, actividad triádica o, en la terminología semiótica, semiosis. Así, para determinar lo que es un signo, lo fundamental no es la diferencia entre signos y no-signos, debido al hecho de que cualquier cosa puede ser un signo. La distinción fundamental es entre signos «genuinos», las relaciones triádicas, por un lado, y por otro, lo que Peirce llamó signos «degenerados», los múltiples tipos de relaciones diádicas y monádicas, donde el componente racional, de terceridad, está subdesarrollado ${ }^{10}$. En resumen, no cabe duda de que en la semiótica, tal como fue concebida por Peirce, el principio básico no es el concepto del signo, sino el de la acción del signo, o semiosis.

La segunda pregunta es en realidad la más interesante de las dos: ¿Cuáles son las características fundamentales de un signo, como acción triádica que es? Sintetizando el problema se puede decir que lo que lo caracteriza es su capacidad de, primero, representar otra cosa y, luego, de ser descodificado, comprendido e interpretado como tal.

10 Para una discusión de los signos degenerados tal como fueron concebidos por Peirce, véase Gorlée 1990 (y las referencias dadas en la bibliografía de este artículo). Añadiré aquí, que desde el punto de vista de la semiótica de Peirce, la semiología, de inspiración saussureana, con su marcado dicotomismo, está regida por signos y argumentos degenerados. Véase, para esto. Gorlée (en prensa). 
Si bien en el curso de su vida intelectual Peirce reformuló con frecuencia su definición del signo, la siguiente, de 1897, es quizás la más generalmente conocida:

\begin{abstract}
Un signo, o representamen, es algo que, para alguien, representa o se refiere a algo en algún respecto o carácter. Se dirige a alguien, esto es, crea en la mente de esa persona un signo equivalente, o, tal vez, un signo más desarrollado. El signo creado es lo que yo llamo el interpretante del primer signo. El signo viene en lugar de algo, su objeto. Viene en lugar de ese objeto, no en todos los aspectos, sino sólo con referencia a una especie de idea, que a veces he llamado el fundamento del representamen. $(C P: 2.228,1897)$
\end{abstract}

Esta definición implica ya que el fundamento, además de ser un primero, es también el primer elemento de la relación del signo. Implica además que el objeto, que es un segundo, es el segundo elemento de la relación del signo; y el interpretante, un tercero, el tercer elemento de la relación del signo. Cinco años más tarde, Peirce llegaría a asociar de modo explícito los elementos de su definición del signo con los tres modos ontológicos, así:

Un Signo, o representamen, es un primero que está en una relación genuina, triádica con un segundo, llamado su Objeto, de tal modo que es capaz de determinar que un tercero, llamado su Interpretante, asuma la misma relación triádica con su objeto que tiene el signo con el mismo objeto. (CP:2.274, 1902)

Un signo consiste en la interacción significativa entre un primero, un segundo y un tercer elemento, en la que el tercero es el elemento mediador entre el primero y el segundo, creando la relación sígnica, que es una tríada indisoluble. El primero consiste en la naturaleza del signo mismo: sus propias cualidades inherentes, su estructura física y/o composición material. Sin embargo, se llama también primero al signo como tricotomía, como relación triádica: «Un signo es una suerte de primero [que] pone un segundo, su objeto, en relación cognitiva con un tercero...» (CP:8.332, 1904). Efectivamente, para Peirce, tal «cognición», pensamiento $o$ actividad mental, no está

... necesariamente conectada con un cerebro. Aparece en la labor de las abejas, en la cristalización y por todas partes en el mundo puramente físico; y no se puede negar su existencia real, como tampoco puede negarse que los colores, las formas, etcétera, de los objetos existan realmente. (CP:4.551, 1906) 
Como quedó demostrado arriba, el signo (en sentido estricto) aparece como el primer elemento en la tríada semiótica; pero su carácter de primeridad no impide que se presente otra vez en tres modos de ser diferentes -como «cualisigno», «sinsigno» o «legisigno». Ésta es la primera tricotomía de signos de Peirce. Según Peirce,

... en primer lugar, un signo puede, dentro de su propia primeridad, ser una mera idea o cualidad del sentimiento [un cualisigno], o puede ser un «sinsigno», eso es, una entidad individual, o puede ser (como una palabra) un tipo general («legisigno») que rija a las entidades. (MS914:3, hacia 1904)

\title{
En la interpretación de Savan, un cualisigno es
}

\begin{abstract}
... un signo que significa mediante una cualidad abstraíble que posee en sí, mediante la primeridad de esa cualidad, separada de toda relación empírica o espaciotemporal que esa cualidad pueda tener con cualquier otra cosa. Por ejemplo, empleo una muestra de color para identificar el color de una pintura que quiero comprar. La muestra estará, quizás, hecha de cartón, será rectangular, estará sobre una mesa de madera, etc., etc. Pero sólo el color es, en la muestra, lo esencial como signo del color de la pintura. O supongamos que soy profesor de natación y enseño alguna brazada particular a un alumno para que él la imite. Aquí hay también muchos aspectos de mi acción que no son oportunos para el caso. Lo esencial en ella como signo es la particular anchura del movimiento de mi brazo. Siempre que una cualidad funciona como un signo que ha de ser copiado, imitado, remendado o reflejado, funciona como cualisigno. (Savan 1987-1988:20) ${ }^{11}$.
\end{abstract}

«Cuando hablamos de cualidad», continúa Savan, «pensamos primero en las cualidades sensoriales simples: color, olor, sonido, etc.» (Savan 1978-1988:29), eso es, en lo que se refiere al signo, como primero que es, en su primeridad:

La percepción de cualquier cosa individual o colectiva nos ofrecerá alguna cualidad abstraíble. Podemos hablar, y efectivamente hablamos de cualidades complejas del paisaje («alpino», «tropical») o de cualidades de personas humanas («napoleónico», «charlotesco») 12. (Savan 1987-1988:20).

Al cualisigno sigue el sinsigno ${ }^{13}$, que, en palabras de Peirce, es la «cosa o suceso realmente existente, que funciona como signo» (Peirce

11 Nótese el curioso paralelismo entre este ejemplo, del profesor de natación, y sus homólogos gimnásticos que sirvieron de ejemplo a Wittgenstein ([1953]1968:1:630) y Goodman ([1968]1985:63), que discutí en mi artículo «Wittgenstein and Peirce: Le jeu de langage» (Gorlée 1989).

12 En un contexto español sería expresiva la cualidad de «quijotesco».

13 Peirce explicó en varias ocasiones que el prefijo sin- significa aquí «que sólo existe una vez», como en ingl. «single, simple», y latín «semel [y simul]» (Peirce 1955:101, hacia 1903;cf. $C P: 8.334,1904)$. 
1955:101, hacia 1903). Para ser sinsigno, eso es, para encarnar un primero bajo su aspecto de segundidad, la «cosa o suceso» debe ser un signo precisamente porque existe como una cosa o suceso individual. Un sinsigno depende tanto de un lugar como de un tiempo, siempre ocurre en un cierto contexto, en el cual ocasiona una acción:

\begin{abstract}
Son sinsignos las muestras de roca lunar analizadas por los científicos espaciales. Cada detalle, cada rasgo peculiar de la roca lunar queda registrado, analizado y utilizado como indicio de la estructura y la historia de la luna, la Tierra y el sistema solar... [Otro ejemplo de un sinsigno es] la luz roja como señal de tráfico..., [que] no indica stop si se trata de una lámpara de decoración de color rojo, ni si estuviera instalada en un prado de vacas u observada por el guardia de tráfico desde un helicóptero sobrevolando el lugar a escasos metros del suelo. (Savan 19871988:21-22).
\end{abstract}

«[E]n tercer lugar, es de la naturaleza de un tipo general cuando yo lo llamo legisigno» (CP:8.334, 1904); entonces, su carácter general, regular, de ley hace que sea un signo. Todos los signos lingüísticos pertenecen básicamente a esta tercera categoría, pues representan el signo, que en sí es un primero, en su terceridad. Peirce no deja en este asunto lugar a dudas, y es importante subrayar este rasgo fundamental de los signos lingüísticos ${ }^{14}$. Para comprobar si algo es general o no, mírese si es repetible y conserva su identidad en las reproduccciones, o si es una cosa, fenómeno o suceso único e individual. Está claro que los signos lingüísticos que los humanos utilizamos pueden reproducirse y que la misma palabra, puede pronunciarse o escribirse muchas veces, apareciendo en cada realización como la misma palabra. Peirce llamó «réplicas» a estas reproducciones.

\title{
OBJETO
}

Después de discutir el signo en la sección anterior, examinaremos ahora brevemente su correlato, el «objeto». El objeto o referente del signo está representado y significado por el signo. Un objeto puede ser real o ficticio, eso es, creado específicamente como elemento en una relación sígnica: «La palabra signo será utilizada para denotar un objeto percepti-

14 Conforme a la doctrina peirceana, Pharies afirma que «Todos los signos lingüísticos, tengan la forma o el significado que tengan, se refieren a sus objetos principal y necesariamente en virtud de una convención» (Pharies 1985:44). A pesar de la amplitud del título de su libro, Charles S. Peirce y el signo lingüístico [Charles S. Peirce and the Linguistic Sign], Pharies se limita aquí a los signos lingüísticos léxicos, o palabras. 
ble o sólo imaginable...» (CP:2.230, hacia 1897). El signo es creado porque se establece una relación de representación; así que algo que no representa a otra cosa, su objeto, no es signo. Así, para ser un signo, un retrato tiene que representar a alguien - la persona retratada, real o imaginaria, y cuya existencia es anterior a la del signo. Y para que sea un signo, un mapa tiene que representar a algún territorio, real o imaginario. Primero existe o se imagina un objeto, luego se crea el signo que lo represente. Esto implica que el signo nunca coincide ni concuerda con el objeto, sino que el signo se halla influido e inspirado por (Peirce solía decir: «determinado por») el objeto. El signo es el elemento pasivo, el objeto es el elemento activo, el que determina al signo. Sin embargo, el objeto está ausente y sólo se puede conocer al objeto a través del signo, estudiando el signo y su contexto. Peirce escribía en el famoso MS318:

...cuando hay tanto un emisor como un intérprete, [el objeto] es lo que aquél trae en la mente, pero que no se le ocurre expresar, pues bien sabe que el intérprete comprenderá a qué se está refíriendo, sin necesidad de mencionarlo. Me refiero aquí a casos en los que el signo se presenta aislado, sin contexto. Así, cuando el emisor dice «¿Qué día más espléndido!», no está imaginando la remota posibilidad de que el intérprete piense que se trata de un mero deseo de un día espléndido que hubiera sentido un finlandés en el Cabo Norte el día 19 de abril de 1776. Naturalmente, la observación se refiere al tiempo atmosférico que está haciendo aquí y ahora, el tiempo espléndido que es el ambiente que está influyendo tanto en él como en el intérprete, la sensación inmediata del tiempo que ambos interlocutores están experimentando en común. Los fósiles marinos hallados en una roca, considerados como un signo de que el nivel del mar fue en algún momento más alto que los niveles donde los fósiles se depositaron, se refieren a una fecha lejana pero indefinida. Aquí no hay emisor; pero por más esencial que fuera para la significación del signo, esta información podría ser la que se callaría un emisor que hubiera producido y construido tal signo para dar a la raza humana una primera lección de geología. Siempre que un signo forma parte de otro signo mayor, existe un contexto; y es en aquel contexto donde probablemente habrá que buscar el [objeto], o al menos una parte de él... (MS318:69-70, 1907).

Cada nueva semiosis añadirá nuevos elementos de información sobre el objeto, que así va revelando poco a poco su auténtica naturaleza al observador/intérprete. Pero si signo y objeto fueran una misma cosa, el signo no aludiría ni señalaría a ningún objeto, y así perdería su capacidad de significar, de transmitir un mensaje: pues «un Objeto que sólo se muestra a sí mismo no representa nada» (MS634:21, 1909). Al producirse tal autorreferencialidad entre signo y objeto, el proceso semiósico se quedaría inevitablemente paralizado.

Peirce distinguía dos objetos en la semiosis: por una parte, el objeto tal como está representado directamente en un determinado signo, el «objeto inmediato», $y$, por otra, el objeto que no está inmediatamente presente y perceptible, el denominado «objeto dinámico». Ambos objetos pueden ser, y efectivamente son muchas veces, muy distintos uno de otro. 
Para conocer el objeto inmediato, el signo es reconocido en su apariencia directa, inmediata. Representa el objeto, que es un segundo (el segundo correlato de una relación triádica), en su aspecto de primeridad; puede, en principio, ser una cualidad, un existente individual o una ley $(P W: 33,1904)$. Mientras el objeto inmediato es el objeto que el signo, por decirlo así, lleva dentro, «la idea en la cual el signo está fundamentado» (MS318:70, 1907), el objeto dinámico es «aquella cosa o circunstancia real en la cual aquella idea está fundamentada o bien cimentada» (MS318:70, 1907). El objeto dinámico no está inmediatamente presente, pues representa el objeto, cual segundo, en su aspecto de segundidad. Es «el objeto fuera del signo» (MS318:70, 1907), la fuente de información e inspiración que está detrás del signo. Decía Peirce: «El signo lo indicará [al objeto dinámico] por algún indicio; y este primer indicio, o mejor su substancia, es el objeto inmediato» $(P W: 83,1908)$. Si bien el objeto dinámico está expresado por el signo sólo de forma indirecta, la observación minuciosa del signo en su contexto, junto con lo que puede llamarse «experiencia»y, en palabras de Peirce, «observación colateral, ayudada por imaginación y pensamiento, normalmente resultarán en alguna idea [del objeto dinámico]» (MS318:77, 1907).

Como nota final podría añadir que el objeto dinámico —el objeto tal como es en sí, abstraído de su materialización y función en un determinado signo - corresponderá a la suma total de las ocurrencias, en cada signo, del objeto inmediato. Y se llega al conocimiento del objeto dinámico, el sentido auténtico del signo, mediante un proceso de semiosis, el «estudio ilimitado y definitivo» (CP:8.183, s.a.) del objeto inmediato tal como se lo reconoce en su contexto espacio-temporal. Esto implica que cuanto más conocimiento general se tiene de un cierto fenómeno, suceso, etc., tanto más coincidirán los objetos inmediato y dinámico.

Referido a su objeto dinámico, un signo puede ser un «icono», «índice» o «símbolo». Ésta es la tricotomía peirceana más generalmente conocida, y asimismo la que, según el mismo Peirce, «parece fuera de toda crítica» (MS339C:449, 1905).

\footnotetext{
Un signo puede referirse a un objeto en virtud de una similitud («semejanza») entre uno y otro (icono), en virtud de una conexión contextual existencial o contigüidad espacio-temporal (física) entre signo y objeto (índice) o por virtud de una ley general o convención cultural que hace que el signo sea interpretado como referido a ese objeto (simbolo). (CP:2.247-2.249, hacia 1903).
}

No cabe duda que para Peirce un icono equivale a un primero, un índice, a un segundo, y un símbolo, a un tercero: 
En los tres órdenes de signos - Iconos, Índices, Símbolos- puede observarse una progresión regular de uno, dos, tres. El Icono no tiene una conexión dinámica con el objeto que representa; sucede simplemente que sus cualidades se asemejan a las del objeto y excitan sensaciones análogas en la mente para la cual es una semejanza. Pero en realidad no está conectado con aquél. El índice está conectado físicamente con su objeto; forman una pareja orgánica, pero la mente que lo interpreta no tiene nada que ver con esa conexión, salvo advertirla una vez establecida. El símbolo está conectado con su objeto en virtud de la idea de la mente utilizadora de símbolos, sin la cual no existiría tal conexión. (CP:2.299, hacia 1895).

\section{Según el texto de mi artículo de 1987,}

...un signo icónico, como son un retrato o un mapa, representa su objeto en virtud de su similitud con él. Fuera de eso - eso es, en sí y por sí- un icono, como primero que es, no asevera nada: «Pues un icono puro no hace ninguna distinción entre sí mismo y su objeto. Representa todo lo que pueda representar, todo lo que tenga parecido con él, sin mirar más allá» ( $C P: 5.74)$. Es la imagen reflejada del objeto significado. Decía Peirce que «La única manera de comunicar directamente una idea es por medio de un icono» ( $C P: 2.278$ ), pues un icono ya exhibe su propio significado sin que sea necesario interpretarlo expresamente.

Mientras los iconos destacan la semejanza, a partir de los índices va destacándose la diferencia. El índice guarda con su objeto una relación causal y real; por consiguiente, sólo puede aseverar algo en la medida en que lo señala directamente. El segundo significado está material o virtualmente presente. El índice favorito de Peirce es la veleta, que denota su objeto, la dirección del viento. Otros ejemplos de índices son, por ejemplo, el humo significando fuego, la fiebre significando enfermedad, los nombres propios y los pronombres demostrativos. Suele ser relativamente sencillo interpretar un mensaje indicial; su interpretación es «natural».

Signos genuinos son símbolos. Son los únicos signos triádicos, pues para actuar como signos —es decir, para representar a otra cosa y ser interpretados como talnecesitan ser interpretados según alguna regla previamente acordada. La regla, aquí, no es de origen natural (como en el caso de los índices) sino cultural. El objeto mismo está ausente, lo que permite a los símbolos engañar y mentir. El significado de un símbolo es una mera conjetura, a menos que haya un significado que sea el producto de mutuo consenso, mientras dure. La naturaleza arbitraria de la conexión entre símbolo y su objeto hace que la regla consensual de interpretación sea susceptible de cambiar y reemplazar por otra, por voluntad de las partes interesadas y al menor descuido de las personas ajenas al poder. Según este mecanismo puede una paloma significar paz, y un trozo de tela atada a un palo puede simbolizar la patria y conmovernos. Así, también, significan los signos linguiísticos; pues como cualquier signo lingüístico puede, en principio, representar cualquier objeto, la lengua es un sistema de signos simbólicos. (Gorlée 1987:48)

Hay que añadir aquí que los tres tipos de signos comentados con anterioridad no son mutuamente exclusivos y que un mismo signo puede funcionar ( $\mathrm{y}$ a menudo funciona) al mismo tiempo como icono, índice $\mathrm{y} / \mathrm{o}$ símbolo. En palabras de Peirce:

La huella que Robinson Crusoe encontró en la arena,..., era para él un índice de que en su isla había alguna criatura, y al mismo tiempo evocaba, en calidad de símbolo, la idea de un hombre. (CP:4.531, 1906) 
Peirce hubiera podido completar esto añadiendo que, en cuanto a la forma, la huella era naturalmente un icono de algún pie humano.

\section{INTERPRETANTE}

Peirce insistía en que «nada es un signo a menos que sea interpretado como un signo» $(C P: 2.308,1902)$. No basta con que el signo «represente» un objeto; también necesita ser interpretado como tal. Por este motivo, la interpretación es tan esencial para la relación triádica del signo como lo es la representación:

\footnotetext{
Una inscripción nunca interpretada por nadie y que nadie interpretaría nunca, no pasaría de ser unos garabatos fantasiosos, un índice de que alguna criatura había estado allí, pero sin comunicar su significado, ni ser apto para comunicarlo. (NEM4:256)
}

En efecto, el «interpretante» —el signo interpretativo o, en otras palabras, el signo que interpreta un signo anterior- ocupa un lugar destacado en la teoría semiótica de Peirce. En la relación signo-interpretante, el interpretante sigue lógicamente al signo: Peirce decía, otra vez, que es «determinado por» él. El signo actúa sobre el interpretante, transacción en la que el interpretante es el que recibe. Pero una vez producido, el interpretante - tercero en la relación triádica del signo- se convierte otra vez en signo - es decir, primero- de la próxima relación triádica, y así sucesivamente.

Como Peirce escribió a Lady Victoria Welby el día 12 de octubre de 1904, «Un signo media entre el signo-interpretante y su objeto, [siendo aquél] el pensamiento interpretador, también un signo» $(P W: 31,1904)$. Todos los interpretantes son en principio verificables, pues remontándose a sus formas anteriores, ha de encontrarse algún rasgo de la realidad o de la cultura, para el que la serie de interpretantes sirve de continuo comentario interpretativo. Citando a Peirce:

Me parece que la función esencial de un signo es hacer eficaces las relaciones que no son eficaces... El conocimiento es lo que las vuelve eficaces; y conocer un signo equivale a ampliar nuestro conocimiento. $(C P: 8.332,1904)$ 
Cada nuevo interpretante provee información más completa sobre el objeto subyacente, así que la cadena infinita de signos interpretadores señalará su punto final, la verdad. Por lo tanto, el proceso semiósico opera tanto para atrás, hacia el objeto, como para adelante, hacia el interpretante. Peirce explicó el funcionamiento del proceso interpretativo así:

\begin{abstract}
El significado de un [signo] puede ser tan sólo un [signo]. De hecho, no es más que el primer [signo], pensado como si estuviera despojado de su ropaje superfluo. Pero este ropaje nunca puede eliminarse por completo; sólo se lo cambia por algo más diáfano. Así que hay aquí regresión infinita. Al final, el interpretante es tan sólo otro [signo] al cual se entrega la antorcha de la verdad; y en calidad de [signo] tiene a su vez su interpretante. He aquí otra serie infinita. ( $C P: 1.339$, s.a.)
\end{abstract}

Peirce distinguía tres interpretantes sucesivos en la semiosis: de un mismo signo puede partir un interpretante «inmediato», un interpretante «dinámico» y un interpretante «final» 15 . El interpretante inmediato de un signo es, según Peirce,

...un sentimiento producido por él ...un sentimiento que llegamos a interpretar como indicio de que hemos comprendido el efecto del signo, aunque su base de verdad sea con frecuencia muy débil. (CP:5.475, 1907)

Parafraseando a Ransdell (1986b:681-682) se puede decir que el primer interpretante es un mero indicio de la interpretabilidad del signo. Demuestra el interpretante inmediato el poder generativo del signo, revelando - de manera aún bastante vaga e indefinida- el rosario de los posibles interpretantes que el mencionado signo, en determinadas condiciones, pudiera dar de sí; es el interpretante, o signo de terceridad, tal como representa al signo en su primeridad.

El interpretante dinámico va más allá de la posibilidad y es un suceso interpretativo real, que implica algún esfuerzo de tipo mental y/o muscular. Como Peirce explicó a Lady Welby, el interpretante dinámico consiste en

...el efecto directo realmente producido por un signo en un intérprete de este signo ....aquello que es experimentado en cada acto de interpretación y es diferente en cada uno de ellos. $(P W: 111,1909)$

15 Cómo se relaciona ésta con la segunda tríada de interpretantes propuesta por Peirce -los interpretantes «emocional», «energético» y «lógico»--, es todavía tema de debate. Véase, por ejemplo, Eco 1976 y, más recientemente, Ransdell 1986b y Short 1986. 
Mientras el interpretante dinámico puede caracterizarse así por una diversificación de puntos de vista, requiriendo continuo reenfoque, decisión y elección, tales cambios de perspectiva quedan superados al llegar la tercera fase interpretativa, el interpretante final, cuya esencia es la univocidad, regla y hábito. Debido a la naturaleza teleológica y normativa del concepto peirceano de la interpretación, el tercer interpretante señala «el efecto significativo que el signo produciría en alguna mente, en la cual las circunstancias permitirian surtir su efecto completo» $(P W: 110$, 1909); y este interpretante es «el único resultado interpretativo a que todo intérprete inevitablemente llegará si el signo es suficientemente considerado» ( $P W: 111,1909)$. Desde luego, un signo puede ser estudiado y reestudiado muchas veces y desde múltiples perspectivas, produciendo cada vez nuevas interpretaciones. Esto hace que el significado del signo sólo pueda ser conocido por completo en algún futuro hipotético.

El significado de un signo viene así dado por, respectivamente, la intuición, la creencia y/o el hábito que, cada cual a su manera, definen el signo como entidad significativa. Por ejemplo, si alguien sostiene que considera la religión como un asunto que sólo atañe a las personas ignorantes 16 , el significado de esta afirmación (el signo) no es idéntico al referente (su objeto doble, la religión y las personas ignorantes) sino a la regla o el hábito (su interpretante) con la cual, bajo ciertas circunstancias, el objeto sería reconocido, identificado y manipulado como tal. El significado de un signo no está, pues, dado por su(s) objeto(s) sino por su(s) interpretación(es). En esto consiste, en (demasiado) breves y (demasiado) concisas palabras la enseñanza de Peirce, quien, en una carta de su amigo, el filósofo William James, presentó la siguiente escena doméstica a modo de ejemplo para ilustrar esta parte crucial de su doctrina semiótica:

Supongamos, por ejemplo, que yo me despierte por la mañana antes que mi esposa, y que ella se despierte luego y pregunte: «¿Cómo está el día?» Esto es un signo, cuyo objeto expresado [inmediato] es el tiempo que está haciendo, pero cuyo objeto dinámico es la impresión que se imagina que yo haya recibido por haber echado una ojeada fugaz entre las cortinas. Cuyo interpretante expresado [inmediato] es la cualidad del tiempo, pero cuyo interpretante dinámico es el hecho de que yo conteste a su pregunta. Pero, más allá, hay un tercer interpretante. El interpretante inmediato es lo que expresa la pregunta, todo lo que expresa inmediatamente, según tengo formulado arriba, aunque de modo imperfecto. El interpretante dinámico es el efecto real que tiene en mí, su intérprete. Pero su significación, el interpretante último o final es el propósito que ella tiene con su pregunta, el efecto que la respuesta tendrá sobre sus planes para el día inminente. Supongamos que yo conteste: «El día está tormentoso». He aquí otro signo. Su objeto inmediato es la noción del tiempo que está haciendo, en la medida en que es común a su mente y la mía - no como es, su carácter, sino como está, su identidad. El objeto dinámi-

16 Este ejemplo está tomado del titular de un anuncio en The New York Review of Books del 31 de enero de 1991, página 5. 
co es la identidad de las circunstancias meteorológicas reales de aquel momento. El interpretante inmediato es el esquema que ella tiene en su imaginación, o sea la imagen vaga de lo que tienen en común las diferentes imágenes de un día tormentoso. El interpretante dinámico es la decepción o cualquier otro efecto directo y real que tiene en ella. El interpretante final es la suma de todas las enseñanzas, moral, científica, etc., que contiene la respuesta. (CP:8.314, 1909)

La tercera tricotomía de Peirce - «rema», «proposición», «argumento»- se aplica a la relación entre el signo y el tercer interpretante, el interpretante final. Esta tricotomía tiene un especial interés para los lógicos, pues se ocupa precisamente del tipo de signos de los que se sirve el razonamiento lógico, es decir de terceros. Un signo puede estar representado por su interpretante como un signo de posibilidad (rema), signo de realidad (proposición) o signo de verdad (argumento). Un rema, en calidad de signo-interpretante que no puede ser verdadero ni falso, es incapaz de transmitir información acerca del objeto, «permite que su objeto y a fortiori su interpretante sea cualquier cosa» (CP:2.95, 1902). Usado en el razonamiento, el signo remático es un signo de "posibilidad cualitativa» (CP:2.251, hacia 1903), una sugerencia abierta que evoca sensaciones y emociones, es decir atribuye al objeto cualidades generales, flotantes, con una base de verdad muy débil. Esto puede ser ejemplificado mediante el famoso eslogan publicitario «Coke is It» ${ }^{17}$, donde el «It» está sin especificar permitiendo, por lo tanto, a cualquier persona que lo interprete como un signo de cualquier cosa.

En contraste con el rema, que es un tercero bajo su aspecto de primeridad, una proposición (también llamada por Peirce «dicisigno») pone énfasis en la segundidad de su carácter fundamental de terceridad. Una proposición es, como decía Peirce, «un signo que indica, por separado, su objeto. Así, un retrato que lleva abajo el nombre del original, es una proposición» $(C P: 5.569,1901)$. Una proposición da información sobre su objeto, pero no es, en palabras de Peirce, «una aserción, sino un signo capaz de ser aseverado... Uno recibirá los castigos sufridos por un mentiroso si la proposición aseverada resulta falsa» $(C P: 8.337,1904)$. Como signo-interpretante de existencia real que es, una proposición ofrece, en la doctrina de Peirce, un juicio lógicamente controvertible y rectificable; puede ser afirmada pero también negada.

Por último en la tríada, un argumento es «un signo que representa de forma nítida el interpretante, llamado su conclusión, que pretende determinar» $(C P: 2.95,1902)$. En el pensamiento lógico, un argumento equivale para Peirce a «una argumentación o afirmación proyectada expresa-

17 Debo este sugestivo ejemplo a mi amigo danés, el eminente estudioso de Peirce, Jörgen Dines Johansen. 
mente para conducir a una creencia dada» (MS599:43, hacia 1902). Un argumento ofrece una conclusión cierta destinada a dar la verdad objetiva y final: «para su interpretante, es un signo de ley» $(C P: 2.252$, hacia 1903). Peirce decía que

...en un sinnúmero de asuntos ya hemos alcanzado la opinión final. ¿Cómo sabemos eso? ¿Es que nos creemos infalibles? En absoluto; pero aun desechando por probablemente errónea una milésima o incluso una centésima parte de las creencias hoy consideradas indudables, permanecerá una gran multitud de ellas, donde la opinión final está alcanzada. Cada directorio, guía, diccionario, historia y obra científica está repleto de tales hechos. (MS1369:24-25, 1885)

Mientras una proposición refleja una verdad más fuerte que un rema, un argumento es el hábito infalible, inquebrantable, el que hace redundante cualquier intento de superarlo. De los tres ofrece el argumento el coeficiente más alto de verdad objetiva. Como «[L]as premisas de un argumento son un signo de la verdad de la conclusión» (MS283:107, 19051906), no hay en el sistema nada que lo contradiga y puede desarrollar todas sus consecuencias a todos los niveles.

En la lógica, un argumento es ejemplificado por los tres modos de argumentación - abducción, inducción, deducción-. Como un signo interpretante puede ser inferido del signo primario abductiva, inductiva o deductivamente, las conclusiones inferenciales son intepretantes especialmente singularizados entre otros interpretantes posibles. Si borramos el propósito peculiar de un argumento, se convierte en proposición, y si borramos la(s) entidad(es) deíctica(s) de una proposición, se convierte en rema. Una proposición es, en términos lógicos, un argumento truncado; y un rema es tanto un argumento truncado como una proposición truncada. Según Peirce,

Lo que queda de una proposición después de cancelar su sujeto es... un rema llamado su predicado. Lo que queda de un argumento cuando se cancela su conclusión es una proposición llamada su premisa o (dado que comúnmente es copulativa) más corrientemente sus premisas.. ( $C P: 2.95,1902)$.

Los remas pueden ser no-relativos, monádicos (con un solo espacio en blanco) o pueden ser relativos: diádicos (con dos espacios en blanco) 0 triádicos (con tres espacios en blanco): «__ es negro» muestra sólo la cualidad de negrura, "__es un perro», sólo la idea de lo canino, «__es o blanco o negro», "__pega a__», «__ da___ ___". A fin de crear una frase o aserción completa, los espacios en blanco se han de rellenar con alguna entidad indicial (también llamada por Peirce hecceidad) tal como 
uno o más nombres propios o sustantivos: Esto añade un sujeto ${ }^{18}$ a la enunciación, la trama narrativa que falta precisamente en un signo remático:

Una proposición consiste en dos partes, el predicado que suscita algo a modo de imagen o sueño en la mente del intérprete, y el sujeto o sujetos, cada uno de los que sirve para identificar algo que es representado por el predicado. (MS280:34, hacia 1905)

Un argumento es, aquí, el elemento final, el que representa el punto de vista pragmático significado por el emisor en el mensaje. Esto se logra añadiendo al universo de cosas concretas y sus cualidades «un símbolo que indica por separado según qué signo la proposición tiene que interpretarse» (MS399b:299, 1898). En un mensaje lingüístico, el argumento puede ser un mandato, una pregunta, una afirmación $\mathbf{u}$ otro acto lingüístico ${ }^{19}$.

\section{SEMIOSIS}

La semiosis consiste en interpretación de signos. Como he señalado arriba, ha de considerarse como un proceso triádico, una interacción significativa entre tres elementos: el signo - «algo que representa algo para alguien en algún aspecto o carácter», su fundamento $(C P: 2.228,1897)$, el objeto - lo que es representado por el signo- y el interpretante - otro signo, que es causado por el primer signo en la mente del que lo interpreta-. La semiosis es la mediación significativa de éste (el signo interpretante) entre aquellos (el signo y el objeto). Citando palabras de Peirce, la semiosis es

... una acción, o influencia, que es, o implica, una cooperación de tres sujetos, como son un signo, su objeto y su interpretante; y esta influencia tri-relativa no puede de ningún modo resolverse en una acción entre pares. (CP:5.484, 1907)

18 «Los sujetos son las indicaciones de las cosas de las que se habla, los predicados, las palabras que afirman, cuestionan u ordenan lo que se pretende» $(C P: 3.419,1892)$. El sujeto peirceano es un concepto lógico que incluye y reúne las funciones gramaticales de sujeto y objeto (directo e indirecto). Véase, por ejemplo, $M S 280: 34-35$, hacia 1905, donde Peirce se apoyaba en esto para su sistema de los grafos existenciales.

19 Acerca de los tempranos avances de Peirce en el ámbito de lo que más tarde sería la teoría de los actos de lenguaje [«speech act theory»], véanse Brock 1981 y Hilpinen 1982. 
La semiosis se produce según tres grados interpretativos en que las creencias van sucesivamente «fortaleciéndose». Estos grados corresponden a la primeridad, segundidad y terceridad. Primero viene la hipótesis, lo que «puede ser» (o «puede no ser»); segundo, el experimento, lo que «realmente es»; y tercero, el hábito, lo que «ha de ser».

El denominado interpretante final es la regla que rige y fija el significado presente y futuro de un signo; le sirve de ley interpretativa. Transformar la semiosis en una operación destinada a dar respuestas definitivas y finales sería, sin embargo, contraproducente y hasta paradójico. Pues negando a la semiosis su naturaleza ilimitada e infinita, se le quita un rasgo distintivo: la posibilidad de que cualquier receptor/intérprete presente o futuro ponga nuevamente en movimiento el proceso interpretativo, convirtiendo un interpretante dado en un nuevo signo y produciendo otro interpretante, el resultado de una nueva semiosis. Este nuevo interpretante puede a su vez convertirse en signo para así producir otro interpretante, y así seguido: «Hay una serie infinita de signos» decía Peirce «en el mismo sentido en que Aquiles recorre una serie infinita de distancias alcanzando la tortuga» (MS599:31, hacia 1902).

Por eso, Short (1986:119ss.) introduce la noción de interpretante lógico «no último», que corresponde a la peirceana «opinión final» pero sin por eso dejar de estar en una relación triádica viva. Tal interpretante sería entonces anterior al interpretante lógico último, entidad esencialmente hipotética en la cual el proceso semiósico se quedará paralizado, porque el signo se ha hecho transparente, coincidiendo con el objeto. Tal concepto evolutivo de la semiosis coloca, en potencia, si no de hecho, al signo en el marco de una secuela infinita de signos, cada uno de los que interpreta al signo anterior. Para revitalizar e insuflar nueva vida en el signo hace falta que la semiosis no cese, que sea procesualidad teleológica y continua.

Peirce no incluía al consumidor del signo - su lector, oyente u otro intérprete- como cuarto elemento de la semiosis, además del signo-interpretante. Tal «omisión» no quiere decir que Peirce no reconociera la existencia de tal intérprete, pues en algunas ocasiones hizo referencia en sus escritos a un intérprete humano. Según parece, Peirce no pensaba aquí en una persona particular ni en una mente específica, sino en un organismo pensante del tipo que fuera - también denominado por Peirce «cuasi-mente» o «cuasi-intérprete»-. Dado que la mente humana no es, en la doctrina semiótica de Peirce, requisito indispensable para la semiosis, son los metafóricamente llamados «teatros de la mente» (MS318:55, 1907) y las «candilejas de la conciencia» (MS339c:505, 1905) los que hacen posible que el signo se desarrolle a sí mismo y que realice en este empeño evolutivo su potencial de significar revelando el objeto. Esto no impide que algún mecanismo interpretador tenga que estar implícito, de algún modo, en la estructura triádica (y no tetrádica) del signo. Pues no 
mediando e interviniendo alguna conciencia interpretadora - sea real o potencial, humana o no humana - no puede haber acción sígnica, ni interpretación, ni, por ende, semiosis.

\section{EL SIGNO LITERARIO}

Hemos visto hasta ahora cómo la doctrina semiótica de Peirce - paradójicamente no-doctrinal, triádicamente evolutiva y radicalmente empírica- permite relacionar la fenomenología y la ontología, modos de conciencia y modos de ser. Los fenómenos de la realidad - de los cuales los fenómenos literarios pueden servir de ejemplo- cobran sentido al ser procesados por alguna mente interpretadora. Ésta, que en el caso de los signos literarios es humana (o, tal vez, una máquina programada por una mente humana), será naturalmente susceptible de aciertos y equivocaciones: pero, según la semiótica peirceana, la obra literaria tiene por único deseo encontrar una y otra vez a una mente que tenga voluntad y preparación para producir un interpretante de ella. Pues la obra literaria es un signo: si no es interpretada, se muere. La vida de la literatura depende de su interpretación.

De entrada, espero que se me permita una simplificación facilona, pero necesaria para no embarcarme en una discusión que desbordaría los límites del presente ensayo. Definiré el arte literario, o «lo literario», como artificio o "ficción» verbal induciéndonos a suspender y abandonar la preocupación, constante y natural en el hombre pensante, por la función social y de veridicción del lenguaje, y a considerar este instrumento primordial de la comunicación interhumana desde una perspectiva puramente estética.

Como se ha indicado al principio de este ensayo, Peirce había, en sus propias palabras - medio sinceras, medio irónicas - «terriblemente descuidado» ( $C P: 2.199$, hacia 1902) el estudio de la estética. En el sistema peirceano de las ciencias normativas, la estética representaba la primeridad y, como tal, constituía el fundamento de las demás ciencias normativas: la ética - segundidad - y la lógica - terceridad-20. El relativo descuido, por parte de Peirce, de los signos estéticos no quita para que su filosofía semiótica ofrezca un método universal que es perfectamente aplicable al estudio de los fenómenos - sumamente específicos, en el panorama de los signos posibles- del arte verbal. Efectivamente, el sig-

20 Para una discusión más detallada de las ciencias normativas en su relación con las categorías, véase Potter 1967:28-51. 
no literario ocupa, aunque implícitamente, un lugar destacado en la doctrina peirceana de los signos: en su sentido más general tiene que ser clasificado en ella como legisigno simbólico remático (o símbolo remático) (Sheriff 1989:75). Tal calificación es, desde luego, susceptible de matizaciones según los usos más específicos que se hagan del signo literario.

El signo literario -el texto, supertexto, o subtexto literario- es legisigno pues es lingüístico $\mathrm{y}$, por ende, general y reproducible. Mediante sus signos de terceridad cada réplica - cada soneto individual y sus partes, cada comedia, etc. - transmite el mismo (o «mismo») mensaje que el «modelo» u «original». El signo literario es simbólico porque es un signo de ficción y sólo puede simbolizar su objeto dinámico (o contexto situativo) ausente, de forma abstracta y convencionalizada. Para introducir el mundo real y referirse a objetos determinados, el signo literario tiene que hacer uso de índices. Los índices crean para tales objetos un referente concreto: en ellos radica la diferencia entre el discurso fáctico y el ficticio. Como signo remático, el signo literario es un tercero bajo su aspecto de primeridad. El signo literario transmite -es decir, «traduce» en signos verbales- impresiones sensoriales. El que sea un signo estético quiere decir que evoca en el receptor sentimientos y cualidades, pero sin describir ni prescribir. Como rema que es, el signo (-interpretante) literario propone un significado posible e hipotético, pero nunca puede dar un significado final. Tal ambigüedad interpretativa - el carácter radicalmente abierto de su interpretación- es, sin embargo, una característica esencial del arte verbal (y del arte no-verbal) que, gracias a ella, ofrece un reto perpetuo a la ingeniosidad de su público - presente, pasado y futuro- de intérpretes.

Como la libertad referencial del rema es, por lo menos en principio, ilimitada y no le preocupa la verdad, el rema es un signo introductor, la primera fase de una semiosis genuina. Es justo recordar, por este motivo, que el discurso ficticio de los signos literarios tiene por objetivo final construir una estructura argumentística que ofrezca argumentos referidos a la experiencia y conducta humanas. Éstas serán siempre variopintas e inaprensibles, pero en el marco de la semiótica peirceana son, por lo menos en principio, racionalizables, aunque en su doble vertiente real e imaginada siempre desbordarán los límites que puedan imponerles los signos lingüísticos. Bien es verdad que la terceridad - la lengua - constituye el ingrediente esencial del discurso literario; pero la peculiaridad de la terceridad consiste precisamente en que puede representar simbólicamente a la primeridad. El arte literario usa signos linguiísticos particularmente para «mostrar, reflejar y simbolizar, de manera inmediata, la cualidad de la conciencia» (Sheriff 1989:89). 


\section{GÉNEROS LITERARIOS}

En las humanidades suele usarse el concepto de género en un sentido estricto, referido a la clásica tripartición, en la literatura, entre épica, dramática y lírica. Sin embargo, en las discusiones al respecto no siempre se tiene debida cuenta de que hablar sobre «lo épico» o sobre «lo dramático» es algo distinto de hablar sobre «la novela» o sobre «la comedia» (Hempfer 1986:282): en el primer caso se trata de

... un número más o menos restringido de «formas naturales» o «arquetipos» definidos como ideas platónicas, constantes antropológicas, tipos de visión del mundo [«Weltanschauungstypen»] etc., que hacen que la teoría de los géneros trascienda a una ontología fundamental. (Hempfer 1986:282)

\section{En el segundo caso se trata a los géneros como}

... grupos de textos históricamente limitados ...[,] sistemas evolutivos interrrelacionados, «familias» históricas, tradiciones, convenciones e/o instituciones. (Hempfer 1986:282-283)

Esta distinción se centra en la diferencia entre la «esencia» de los géneros literarios por un lado, y su «función» por otro; distinción que encontramos también, bajo diversas denominaciones en los trabajos de los semiólogos de la tradición saussureana que se han ocupado de este tema 21 .

Lo que interesa aquí es, sobre todo, poner de relieve los géneros literarios según la primera caracterización, como invariantes ontológicas abs-

21 Ducrot y Todorov (1972) hablan de «tipo» y «género». El primer término queda reservado para la poética general, es decir, para la literatura como «lengua», o sistema, donde se refiere inductivamente a la existencia de los géneros como «entidades estructurables»; «género» se refiere al género como fenómeno histórico en la literatura como «habla» literaria, donde postula la existencia de los géneros deductivamente, a partir del corpus textual existente. (Sobre el papel de deducción, inducción y abducción en el pensamiento estructuralista, véase Gorlée [en prensa]). Greimas y Courtés (1979:164) no se limitan a lo literario al proponer criterios para una tipología del discurso. Éstos, basados en «postulados ideológicos implícitos», están culturalmente condicionados, según estos autores, quienes proponen, para la literatura europea moderna, una dicotomía genérica que distingue entre una teoría «clásica» — fundamentada en «forma» vs. "contenido»- y una teoría «posclásica» que, fundada en «cierta concepción de la 'realidad' del referente, posibilita distinguir ... sea diferentes 'mundos posibles', sea encadenamientos narrativos más o menos conformes a una norma subyacente (cf. los géneros fantástico, maravilloso, realista, surrealista)»(Greimas y Courtès 1979:164). Nótese que, a diferencia de la perspectiva peirceana, los criterios manejados aquí son primordialmente temáticos. 
tractas y transhistóricas ${ }^{22}$. Constituyen el marco «universal» en el que se inscriben los géneros concretos, que son colecciones coherentes de textos o supertextos. Número, índole y composición de éstos son naturalmente variables y sujetos a continuas modificaciones y redefiniciones, por lo cual resulta contraproducente e incluso imposible todo intento de fijarlos una vez por todas.

Los modos genéricos no están determinados y definidos por los componentes de una o más obras literarias, sino que son ellos los que determinan y definen la forma, estructura y lógica de la obra literaria, así como su contenido temático. No sólo cada género reúne ciertas características formales que proveen información acerca del status de la obra literaria como vehículo de comunicación interhumana (relación entre emisor y receptor, particularidades del código, función socio-situacional del mensaje); cada género tiene también su particular capacidad - y sus límites- de tratar - es decir, de semiotizar — la realidad. Frente a la infinita variedad de los fenómenos de la realidad, el signo literario hace una selección reflejando una versión filtrada y focalizada de la realidad. Estos dos principios, interactivos, dan una orientación dinámica y generativa al signo literario, cuya composición nunca puede ser mecánica y cuya interpretación es siempre un acto creativo. La obra literaria es pues, en una palabra, semiosis - con todas las implicaciones que el concepto de semiosis pueda tener para el signo artístico-verbal.

Si seguimos a Santaella Braga, la lengua ha de considerarse como «un proceso de codificación de segundo nivel», lo que hace que sea «representación de una representación» o «signo de un signo» (Santaella Braga 1980a:145-146). Este enfoque jerárquico-semiótico implica, entre otras cosas, que podemos aplicar el aparato conceptual de la semiótica al arte verbal, y considerar las categorías universales como modos ontológicos que subyacen a la tricotomía de los modos genéricos —condicionándolos, haciéndolos partícipes de su fuerza significativa e imprimiendo en ellos su sello particular-. Así, los géneros lírico, dramático y épico pueden considerarse como transcodificaciones, dentro del contexto literario verbal, de la primeridad y la segundidad en sus diversos matices. Dado el carácter remático de la relación signo-interpretante final, no es extrañar que el signo literario no llegue a participar plenamente de la terceridad de la semiosis genuina: ésta exige que todos los elementos de la tríada sígnica sean terceros. Si bien el signo literario aspira (como quedó indicado arriba) a crear argumentos (en el sentido peirceano de este término), se caracteriza, significativamente, por su incapacidad de ocupar tal cate-

22 Queda fuera de la presente discusión el estudio, mucho más amplio e intrincado, de las formas concretas en las que tales esencias pueden funcionar, en la literatura, como estructuras sígnicas verbales comunicativas entre un emisor y un receptor. Véase Johansen 1985, 1986, 1988 y 1989. Otro estudio anterior, con interesantes implicaciones para la semiótica literaria, es Stankiewicz 1977. 
goría. Alcanzar la transparencia total, la verdad objetiva, es para el signo literario la meta - pero es una meta ilusoria-.

\section{LIRICIDAD}

Si retomamos la clásica tripartición entre los modos lírico, dramático y épico, podemos ver lo lírico como exponente de la primeridad 23. Como tal, el modo lírico acompaña y entra en todos los géneros y subgéneros literarios concretos, donde muestra la(s) cualidad(es).fundamental(es) del sentimiento expresado. Sin embargo, es en la poesía lírica donde la liricidad tiene su encarnación más pura y típica; allí la univocidad del monólogo ejemplifica las inquietudes subjetivas, emotivas, que están reflejadas, en forma condensada, en este modo literario. Lo lírico es desahogo personal y experiencia privada, que no puede ser razonado sin que pierda su carácter - intuitivo y precognitivo- de signo de primeridad.

Lo lírico crea en la mente del receptor imágenes icónicas que, en el caso de la poesía lírica, son viñetas compuestas. Despliega todos sus efectos sensoriales - sonido, ritmo, forma-- simultáneamente, superpuestos, interpenetrándose, iluminándose y modificándose. La multiplicidad «salvaje» del modo lírico es producto de combinaciones formales nuevas que a su vez producen significados nuevos. (En la poesía las principales novedades son de tipo léxico y en el orden de las palabras.) Los significados del signo (subsigno, supersigno) de liricidad son conjeturas de escasa substancia, propuestas personalizadas y siempre sustituibles por otras.

Posiblemente pueden distinguirse tres tipos de liricidad. Si la poesía lírica representa el primer grado de la primeridad - la primeridad más pura o, desde la perspectiva inversa, la terceridad más degenerada-, lo lírico puede también poseer un (rudimentario) hilo argumental que le presta carácter de segundo grado de primeridad. En la poesía, pero también en los textos publicitarios y en los de las canciones infantiles, pueden encontrarse ejemplos de ambos tipos de liricidad. Existe además una primeridad más genuina y menos degenerada, la del signo verbal lírico que contiene un elemento de terceridad - es decir, de reflexión, crítica e/o ideología- , sin por eso dejar de apelar al puro sentimiento. Esto ocurre en la poesía didáctica y, en general, en el arte verbal que enseña, pero de manera no-racional y no-conflictiva - según es practicado, por ejemplo, en cierta retórica religiosa y política.

23 De ahí el neologismo, a lo Peirce, de «liricidad» (y sus contrapartidas, «dramaticidad» y «epicidad»). 


\section{DRAMATICIDAD}

Lo dramático está condicionado por la segundidad, el modo de ser que incluye y presupone a la primeridad - la cualidad del sentimiento-, pero pone especial énfasis en el aspecto praxiológico, de acción y reacción ${ }^{24}$, que sustituye y complementa al estatismo icónico característico de la primeridad. La dramaticidad es acontecer en el espacio y el tiempo. Allí, en forma de diálogo (triálogo, etc.) «real» —o mejor dicho, con visos de verosimilitud-, se dramatizan, de manera ecléctica, las diversas dimensiones sociales del comportamiento humano en su entorno social. Tal interacción —colisión, roce, acuerdo, etc.- entre una experiencia personal y otra distinta se basa directamente en lo que la experiencia tiene de oposición entre los aspectos fácticos del mundo; representa, por lo tanto, la segundidad de la segundidad.

En el modo dramático hay acción. Ésta sigue una línea narrativa avanzando desde un punto inicial -el planteamiento de una situación problemática - hasta un punto final —el desenlace- La dramaticidad va cristalizándose en cada una de las luchas y los esfuerzos tanto mentales como físicos sufridos por los «actores» implicados, y que éstos intentan superar. Este modo indicial, deíctico constituye el paradigma del género literario teatral 25 (y sus subgéneros) como representación audiovisual de la vida humana considerada como lugar y tiempo de encuentro -0 de conflicto- entre pasiones, acciones y opiniones heterogéneas.

\section{EPICIDAD}

A la luz de la doctrina de las categorías, lo épico representa la terceridad de la segundidad, que establece relaciones significativas entre sucesos espacio-temporales e impresiones sensoriales. La epicidad ofrece un razonamiento más o menos lógico sobre la realidad fenomenológica y sus cualidades. Su forma literaria más típica sería la novela - ese gran invento literario español-. Efectivamente, el mundo literario del Quijote sería un ejemplo típico de lo que aquí se entiende por epicidad. El propósito de lo épico es primordialmente narrativo —es decir, dramático- ; pero más allá de la nota predominante de la dramaticidad descriptiva, lo

\footnotetext{
24 Etimológicamente, el vocablo griego «drama» significa «acción».

25 Etimológicamente, «teatro» - del latín «theatrum», griego «theatron»— significa «espectáculo», refiriéndose sólo a lo visual.
} 
épico demuestra también una postura claramente crítica. El autor -omnisciente o no- deja de vivir directamente la vida de «sus» «actores» y toma cierta distancia que le permite reflexionar, interpretar y comentar. Las opiniones expresadas, explícita o implícitamente, en el signo épico-literario serán racionales y razonadas, por lo menos hasta cierto punto; pero la (relativa) libertad y arbitrariedad del punto de vista -el aspecto de simbolicidad peirceana- puede también convertirse en instrumento de manipulación. Siempre que, en el arte verbal, la epicidad pretende dar la verdad, frisa en la terceridad del discurso «objetivo», coto vedado para el arte. El discurso que deja de ser ficción también deja de ser literario.

Tomando como punto de partida a la tríada de modos literarios y a las categorías ontológicas en las que están inscritos, pueden distinguirse, dentro de cada modo literario, otra vez tres modalidades 26. Así como el modo lírico puede ser ejemplificado por la poesía lírica - correspondiendo a la primeridad de la primeridad-- la segundidad de la primeridad sería, en literatura, la poesía narrativa; y la terceridad de la primeridad, la poesía de tipo didáctico. Y dentro de lo épico se podría decir que en la novela rosa predomina el aspecto de primeridad; en la novela policiaca, el aspecto de segundidad; y en la novela de ciencia-ficción, el aspecto de terceridad.

No sería justo terminar sin apuntar a la posibilidad de que, además de los subtipos dentro de un modo ontológico-genérico, existen también muchas combinaciones transmodales. En ellas se establece un paralelismo con los tipos de signos - genuinos, degenerados, y las múltiples formas sígnicas intermedias-. Así, pueden imaginarse modos literarios en los cuales predomina, por ejemplo, la dramaticidad, con una incidencia adicional e incrustada de la liricidad y/o la epicidad. Sin embargo, adentrarnos en esta compleja problemática nos llevaría demasiado lejos de aquí.

\section{Referencias bibliográficas}

Brock, J. E. (1981): «An introduction to Peirce's theory of speech acts». Transactions of the Charles S. Peirce Society 18-4, 319-326.

Deely, J., B. Williams y F. KRuSE (eds.) (1986): Frontiers in Semiotics (Advances in Semiotics). Bloomington, IN: Indiana University Press.

Ducrot, O. y T. TODorov (1972): Dictionnaire encyclopédique des sciences du langage. Paris: Seuil.

26 Esto ha sido argumentado y elaborado convincentemente en Santaella Braga 1980a. 
ECO, U. (1976): «Peirce's notion of interpretant» Modern Language Notes 91-6, 1457 1472.

Esposito, J. L. (1980): Evolutionary Metaphysics: The Development of Peirce's Theory of Categories. Athens, $\mathrm{OH}$ : Ohio University Press.

EVANS, J. D. Y A. HelBo (eds.) (1986): Semiotics and International Scholarship: Towards a Language of Theory. Dordrecht, Boston y Lancaster: Nijhoff.

Fitzgerald, J. J. (1966): Peirce's Theory of Signs as Foundation for Pragmatism (Studies in Philosophy 1). La Haya/París: Mouton.

Goodman, N. ([1968]-1985): Languages of Art: An Approach to a Theory of Symbols. Indianapolis: Hackett.

GoRlÉE, D. L. (1987): «Firstness, Secondness, Thirdness, and Cha(u)nciness». Semiotica 65-1/2, 45-55.

- (1989): «Wittgenstein et Peirce: Le jeu de langage» Semiotica 73-3/4, 219-231.

- (1990): «Degeneracy: A reading of Peirce's writing». Semiotica 81-1/2, 71-92.

- (en prensa): «Symbolic argument and beyond: A Peircean view on structuralist reasoning». Poetics Today.

Greimas, A. J. y J. Courtès (1979): Dictionnaire raisonné de la théorie du langage. Paris: Hachette.

HempFer, K. W. (1986): «Genre» En Sebeok (ed. gen.) 1986, 282-284.

HilPINEN, R. (1982): «On C. S. Peirce's theory of the proposition: Peirce as a precursor of game-theoretical semantics». The Monist 65-2, 182-188.

JOHANSEN, J. D. (1985): «Prolegomena to a semiotic theory of text interpretation». Semiotica 57-3/4, 225-288.

- (1986): «The place of semiotics in the study of literature». En Evans y Helbo (eds.) 1986, $101-126$.

- (1988): «What is a text? Semiosis and textuality, a Peircian perspective». Livstegn 5/1, 7-32.

- (1989): «Hypothesis, reconstruction, analogy: hermeneutics and the interpretation of literature». Semiotica 74-3/4, 235-252.

Kent, B. (1987): Charles S. Peirce: Logic and the Classification of the Sciences. Kingston/Montreal: McGill-Queen's University Press.

Peirce, Ch. S. (1931-1966): Collected Papers of Charles Sanders Peirce, Ch. Hartshorne, P. Weiss y A. W. Burks (eds.). 8 vols. Cambridge, MA: Harvard University Press $(C P)$.

- (1955): Philosophical Writings of Peirce, J. Buchler (ed.). Nueva York: Dover.

- ([1958]-1966): Charles S. Peirce: Selected Writings (Values in a Universe of Chance), Ph. P. Wiener (ed.), Nueva York: Dover (SW).

- (1977): Semiotic and Significs: The Correspondence between Charles S. Peirce and Victoria Lady Welby, Ch. S. Hardwick (ed.). Bloomington y Londres: Indiana University Press $(P W)$.

- (1979): The New Elements of Mathematics by Charles S. Peirce, C. Eisele (ed.). 4 vols. La Haya, París: Mouton y Atlantic Highlands, NJ: Humanities Press (NEM).

- (1982-1989): Writings of Charles S. Peirce: A Chronological Edition, M. H. Fisch, E. C. Moore, Chr. J. W. Kloesel et alii (eds.). 4 vols. Bloomington, IN: Indiana University Press $(W)$.

- (1986): La ciencia de la semiótica, A. Sercovich (ed.). Buenos Aires: Nueva Visión.

- (1987): Obra lógico-semiótica, A. Sercovich (ed.). Madrid: Taurus.

- (1988): Escritos lógicos, P. Castrillo Criado (ed.). Madrid: Alianza.

- Manuscritos inéditos, Peirce Edition Project, Indianapolis, IN (MS). 
Pencak, W. (1991): «Charles Sanders Peirce, historian and semiotician». Semiotica 83$3 / 4,311-332$.

Pharies, D. A. (1985): Charles S. Peirce and the Linguistic Sign (Foundations of Semiotics 9). Amsterdam/Filadelfia: John Benjamins.

PotTer, V. V. (1967): Charles S. Peirce on Norms \& Ideals. Worchester, MA: University of Massachusetts Press.

RANSDELL, J. (1986a): «Semiotic objectivity». En Deely, Williams y Kruse (eds.). 1986, 236-254.

- (1986b) «Charles Sanders Peirce». En Sebeok (ed. gen.). 1986, 673-695.

SantaElla Braga, M. L. (1980a): «Por una classificaçao da linguagem escrita». En Santaella Braga 1980b, p.. 145-160.

- (1980b): Producao de linguagem e ideologia. Sao Paulo: Cortez Editora.

SAVAN, D. (1977): «Questions concerning certain classifications claimed for signs» Semiotica 19-3/4, 179-195.

- (1987-1988): An Introduction to C. S. Peirce's Full System of Semeiotic (Monograph Series of the Toronto Semiotic Circle 1): Toronto: Victoria College of the University of Toronto.

SebeoK, Tн. A. (ed.) (1977): A Perfusion of Signs (Advances in Semiotics). Bloomington y Londres: Indiana University Press.

- (ed. gen.) (1986): Encyclopedic Dictionary of Semiotics (Approaches to Semiotics 73). 3 vols. Berlín: Mouton de Gruyter.

Sheriff, J. K. (1989): The Fate of Meaning: Charles Peirce, Structuralism, and Literature. Princeton, NJ: Princeton University Press.

ShorT, TH. L. (1986): "What they said in Amsterdam: Peirce's semiotic today". Semiotica 60-1/2, 103-128.

STANKIEwICZ, E. (1977): «Poetics and verbal art». En Sebeok (ed.). 1977, 54-76.

Tordera, A. (1978): Hacia una Semiótica Pragmática. El signo en Ch. S. Peirce. Valencia: Fernando Torres.

Wittgenstein, L. ([1953]-1968). Philosophische Untersuchungen - Philosophical Investigations, G. E. M. Anscombe y R. Rhees (eds.). Traducción G. E. M. Anscombe. Reimpresión. Oxford: Basil Blackwell. 